\title{
Mortality of workers at the Sellafield plant of British Nuclear Fuels
}

\author{
P G SMITH, A J DOUGLAS
}

\begin{abstract}
The mortality of all 14327 people who were known to have been employed at the Sellafield plant of British Nuclear Fuels at any time between the opening of the site in 1947 and 31 December 1975 was studied up to the end of 1983 . The vital state of $96 \%$ of the workers was traced satisfactorily and 2277 were found to have died, $572(25 \%)$ from cancer. On average the workers suffered a mortality from all causes that was $2 \%$ less than that of the general population of England and Wales and 9\% less than that of the population of Cumberland (the area in which the plant is sited). Their mortality from cancers of all kinds was 5\% less than that of England and Wales and 3\% less than that of Cumberland. In the five years after their first employment Sellafield workers had an overall mortality that was $\mathbf{7 0 \%}$ of that of England and Wales, probably due to healthier members of the population being selected for employment. Raised death rates from cancers of several specific sites were found, but only for those of ill defined and secondary sites was the excess statistically significant (30 observed, 19.7 expected). For cancers of the liver and gall bladder there was a significant deficit of deaths (four observed, 10.5 expected).
\end{abstract}

Workers in areas of the plant where radiation exposure was likely were issued with dosimeters to measure their external exposure to ionising radiations. Personal dose records were maintained for workers who entered such areas other than infrequently. Workers with personal dose records ("radiation" workers) had lower death rates from all causes combined than other workers but the death rates from cancer in the two groups were similar. Compared with the general population radiation workers had statistically significant deficits of liver and gall bladder cancer, lung cancer, and Hodgkin's disease. There were excesses of deaths from myeloma (seven observed, $4 \cdot 2$ expected) and prostatic cancer ( 19 observed, 15.8 expected) but these were not significant and there was no evidence of an excess of leukaemia (10 deaths observed, 12.2 expected) or cancer of the pancreas ( 15 observed, $17 \cdot 8$ expected). Non-radiation workers had a significant deficit of leukaemia (one death observed, $5 \cdot 1$ expected) and a significant excess of cancers of ill defined and secondary sites ( 13 deaths observed, 5.8 expected). For no type of cancer was the ratio of observed to expected deaths significantly different between radiation and non-radiation workers. For non-neoplastic conditions radiation workers in general had lower death rates than other workers, and for none of the causes of death examined was the mortality significantly higher among radiation workers. Also there was no significant evidence of a relation between cancers of specific sites and duration of employment at Sellafield as a radiation worker.

Comparisons were made of the mortality of radiation workers who had accumulated different exposures to radiation as measured by dosimeter records. For all causes of death combined there was a significant negative association between death rates and accumulated doses which was no longer present when

\footnotetext{
Department of Epidemiology, London School of Hygiene and Tropical Medicine, London WC1E 7HT

P G SMITH, DSC, reader in tropical epidemiology

A J DOUGLAS, MSC, research fellow

Correspondence to: Dr Smith.
}

exposures in the 15 years preceding death were discounted. There were positive associations between accumulated radiation dose and death rates from bladder cancer, multiple myeloma, leukaemia, and all lymphatic and haematopoietic neoplasms. These were not statistically significant when exposure up to the time of death or up to two years before death was considered. Nevertheless, when exposures recorded in the $\mathbf{1 5}$ years before death were ignored these associations, with the exception of that for leukaemia, became significant. The association of radiation dose with bladder cancer has not been reported in other studies of radiation workers but the findings for myeloma were consistent with the excess reported for radiation workers in the United States.

Excess death rates from all cancers were estimated to be reduced by six deaths per million person years at risk per $10 \mathrm{mSv}$ $(1 \mathrm{rem})$ for radiation accumulated up to the time of death $(95 \%$ confidence limits -22 and 13) and increased by 17 deaths per million person years at risk per $10 \mathrm{mSv}$ for radiation exposure accumulated 15 or more years before death $(95 \%$ confidence limits -30 and 70 ). The findings were compatible with the estimates of the carcinogenic risk of low doses of ionising radiations made by the International Commission on Radiological Protection (about five deaths per million person years at risk per $10 \mathrm{mSv}$ ), but on these data alone it was impossible to exclude with confidence a risk 10-fold higher or the absence of any risk at all.

\section{Introduction}

Many people who have worked at the Sellafield nuclear reprocessing plant have as a consequence been exposed to doses of ionising radiations higher than those likely to be experienced by most other members of the general population. Levels of exposure to external radiation have been monitored by "film badge" dosimeters issued to those who worked in areas of the plant in which radioactive materials were present. Estimates of radiation exposure from analyses of the dosimeter recordings have been used to check that individual exposure levels have been within permissible limits for workers in the industry. These limits are based on estimates of the carcinogenic risks of such exposures made by the International Commission on Radiological Protection.

The estimates of risk to workers exposed intermittently to low doses of radiation have been calculated by the commission (and by other bodies) by linear extrapolation from effects reported in selected groups of subjects exposed to relatively high radiation doses at high dose rates. ${ }^{1}$ The two main groups studied have been the survivors of the atomic bomb explosions in Japan and various series of patients irradiated for benign disease. There is considerable uncertainty, however, regarding the appropriate extrapolation procedure to estimate low dose effects, and while some have argued that the methods used are likely to overestimate the risk associated with such doses, others have argued that the risk estimates may be too low.

It has been recognised that the permissible levels of exposure are such that if the estimates of the carcinogenic risks on which the levels are based are correct, then it is unlikely that an increased cancer risk would be detectable even in a very large workforce exposed for many years at the limit of permissible levels. ${ }^{2}$ None the less, because of the uncertainties regarding low dose effects it has been considered desirable to monitor the disease experience of nuclear workers in case the carcinogenic risks should be found to be 
much higher than anticipated. Data on the mortality of workers at the Hanford nuclear facility in the United States have been analysed by several groups and, though there has been some variance in the interpretation of different analyses, a common finding has been a statistically significant association between deaths from myeloma and radiation dose and a more equivocal association between radiation dose and cancer of the pancreas..$^{3-6}$ Beral et al have reported on the mortality of nearly 40000 employees of the United Kingdom Atomic Energy Authority. ${ }^{7}$ They found no significant or definite association between radiation exposure and myeloma or cancer of the pancreas but did find an association with deaths from prostatic cancer.

We report on the mortality of all people who were known to have worked at the Sellafield plant at any time between the date the site opened and 31 December 1975. The group was smaller than that studied at Hanford and from the United Kingdom Atomic Energy Authority but on average the workers had been exposed to higher radiation doses.

\section{Population and methods}

The Sellafield plant of British Nuclear Fuels is situated on the Cumbrian coast and was opened in 1947. The site was developed originally by the Ministry of Supply for the production of plutonium for defence. By 1952 two nuclear reactors and a spent fuel reprocessing plant were in operation. The reactors and reprocessing plant were subsequently closed and five further reactors (one of which has been closed), a replacement reprocessing plant, various waste treatment plants, and a fast reactor fuel fabrication plant have since been opened (P Mummery, personal communication). The Sellafield plant both reprocesses and stores spent fuel from nuclear power stations in Britain and overseas. Responsibility for the plant was transferred to the United Kingdom Atomic Energy Authority in 1954 and subsequently to British Nuclear Fuels in $1971 .^{8}$

\section{STUDY POPULATION}

In 1976 the National Radiological Protection Board started the National Registry of Radiation Workers. ${ }^{9}$ It was planned that initially the register would include nuclear workers who were alive in 1976 and who were being monitored for radiation exposure. It was proposed to follow up these workers prospectively from 1976 to detect deaths and new cases of cancer. We therefore decided to restrict our retrospective study of the mortality of Sellafield workers to those first employed before 1976. Originally we planned to trace these workers up to the end of 1975 but later the follow up period was extended to the end of 1983 . Thus the study population for the analyses presented here includes all those first employed at Sellafield before 1976, followed up until 31 December 1983.

To identify the population who had ever worked at Sellafield personnel records of the plant were searched by staff of British Nuclear Fuels. Shortly after the plan first opened workers in most departments were allocated a consecutive works number, and in 1954 this system was extended to all departments. Subsequently, each new entrant to the workforce was given the next number in the sequence. Thus it was possible to be reasonably sure whether ascertainment of the study population was complete. For workers who had been expected to start employ ment before 1 January 1976 numbers up to 15042 had been issued. Owing to clerical errors in the personnel office, however, one sequence of 900 numbers was not issued and 25 additional numbers were not used. Eighty nine workers had been issued with two numbers, usually being given a second on re-employment. In 15 instances the second number issued was greater than 15042 . Twenty two numbers were allocated to people who never took up employment or who started after 1975 and one was allocated to a contractor's employee. Records relating to two numbers could not be located. Thus for the 15042 numbers issued 14018 related to workers included in the study. Four additional workers were included who were issued with higher numbers but who started work earlier than originally expected. A total of 305 workers were also included who were found not to have been issued with a number. All of these were first employed before 1961, and all but 23 left employment before the final implementation of the works number scheme in 1954. Only eight of them worked in the plant for more than three years. Thus the total study population consisted of 14327 subjects.

Where possible the full name, sex, and date of birth of each employee were extracted from the personnel records together with a classification as an "industrial" or "non-industrial" worker. The administrative distinction between these two groups was contractual; in general industrial workers were paid weekly whereas non-industrial workers were paid monthly. The latter category included scientific, clerical, and managerial staff. On average the non-industrial worker were of a higher socioeconomic state than industrial workers. No further grouping by socioeconomic state was made in the data included here.

Figure 1 shows the number of workers employed at the plant in each year from 1947 to 1975 . The size of the workforce expanded steadily from when the plan started until 1961, when about 6000 were in employment. The workforce subsequently fell to around 4000 in 1969 and thereafter increased to about 4750 in
1975. Only about $19 \%$ of the total number of workers were women. Of the 11402 men included in the study, $60 \%$ were classified as "industrial" workers; of the women, $52 \%$ were so classified.

For workers first employed before 1976 and whose age and sex were known the average duration of employment at Sellafield up to 1984 was $9 \cdot 2$ years (men $c$ $10 \cdot 3$ years, women $4 \cdot 6$ ). A total of $7 \cdot 3 \%$ were employed for less than three months $\widehat{\supset}$ ( $6.1 \%$ of men, $12 \cdot 4 \%$ of women) and $28.9 \%$ for less than two years $(24.9 \%$ of men, $46 \cdot 2 \%$ of women). Just over half $(53 \cdot 5 \%)$ worked for longer than five years $(58 \cdot 5 \%$ of men, $31 \cdot 3 \%$ of women), $33.9 \%$ for longer than 10 years $(38 \cdot 7 \%, 12 \cdot 8 \%)$, and $\Phi$ $17 \cdot 0 \%$ for longer than 20 years $(20 \cdot 0 \%, 3 \cdot 8 \%)$.

FIG 1-Numbers of male and female workers employed at Sellafield at some time సิ during each year from 1947 to 1975 and numbers of radiation workers.

\section{FOLLOW UP}

An attempt was made to trace records of all workers from the date of their first 윽 employment until 31 December 1983 to identify any who had died in this period. Three different sources of such information were used. The primary method of follow up was through the National Health Service Central Register. Identification details of all workers with known date of birth and sex were sent to the $\bar{O}$ register. If the record of a worker was found in the register it was "flagged" so that if the person died subsequently this would be notified to us and a copy of the death certificate sent. Death certificates were provided by the register for any workers $\vec{\omega}$ found to have died when the initial tracing was made. Except for a short period at $\infty$ the end of the study period, all death certificates were sent to one of us (PGS) by registry staff independently of being forwarded or copied to British Nuclear Fuels. It was thus possible to monitor the information obtained on mortality independently of British Nuclear Fuels to ensure that all relevant deaths were included in the analyses. The NHS Central Register also includes information $\bar{O}$ (albeit incomplete) on dates of emigration from and re-entry to the United Kingdom, and this information was also supplied to us for all workers traced in the register.

In addition to tracing through the register, the names, dates of birth, sex, and, where known, national insurance numbers for all workers were also sent to the records branch of the Department of Health and Social Security. The records $\bar{Z}$ branch attempted to locate each worker in its insurance records and notified us of those whose record could not be traced, whose record indicated that they were still alive, or whose record indicated that they had died. For those recorded as dead it was possible to supply the dates of death but not the causes. These dates were sent to the NHS Central Register in order that the quarterly indices of deaths maintained by the Office of Population Censuses and Surveys might be searched $\frac{\sigma}{3}$ to enable the death certificates to be abstracted. Information on workers was sent to the DHSS in batches from 1979 onwards, and as there was no provision for 8 "flagging" workers in that system the trace information from this source did not 3 extend up to the end of the study period. This has been taken into account in the analyses (see below).

A further source of information was the medical, personnel, and pensions $N$ records of British Nuclear Fuels, from which it was possible to identify both workers who had died in employment or while receiving a company pension and also those still employed by the company.

By integrating the information from these three sources the state of a high proportion of workers was ascertained. In some instances there was conflicting information from the different sources, so that it was necessary to construct a rule $\omega$ for resolving the discrepancies. In summary this was as follows. If a subject was $\sigma$ traced in the NHS Central Register the information from that source was used in the analysis unless the person was recorded as dead by another source (and not dead in the register). In such instances the person was classified as dead if a death certificate could be traced. Those not traced by the NHS Central Register but traced as alive by the DHSS were regarded as alive at the date of the DHSS search. $T$ Those untraced by both the NHS Central Register and the DHSS were classified $\bar{O}$ as dead if a death certificate was available, otherwise as alive at their last work date. Thirty five workers were traced as dead by the DHSS but a death certificate could not be located. Thirty three of these were taken as lost to follow up at the recorded date of death. Two were employed at Sellafield after the recorded date of $\sigma$ death, and we assumed that the DHSS trace information was erroneous in these cases.

Of the 14327 workers included in the study population, $327(2 \cdot 3 \%)$ were excluded from further analysis because either their sex or date of birth was not recorded (table I). Of the remainder, $10442(72.9 \%)$ were traced as alive on 1 January $1984 ; 410(2.9 \%)$ had emigrated and were not known to have returned 
to the United Kingdom before 1984 and were included in the analysis up to the date of emigration; $643(4.5 \%)$ were traced by the DHSS but not by the Office of Population Censuses and Surveys and were excluded from analysis at the date of the DHSS trace; $2277(15.9 \%)$ had died; and $228(1.6 \%)$ could not be traced beyond their date of last employment at Sellafield. A total of 346 subjects were recorded as having emigrated and returned to the United Kingdom at a later date and these were excluded from the analyses for the period that they were away.

\section{CLASSIFICATION OF CAUSES OF DEATH}

The death certificates for the 2277 subjects who had died were coded by the Office of Population Censuses and Surveys according to the eighth revision of the International Classification of Diseases. ${ }^{10}$ Because deaths in the study population occurred over a period when different ICD revisions were in operation, and because of the availability of yearly national mortality data classified according to the ICD revision in use in each year, each death certificate was also classified in this way. This could not be undertaken by the Office of Population Censuses and Surveys as its coding staff at the time were familiar only with the eighth and ninth revisions. We were fortunate, however, in obtaining the help of Ms P Loy, who had recently retired from the Office of Population Censuses and Surveys and had also been a WHO adviser on ICD coding. Ms Loy coded the underlying cause of death for each certificate according to the rules and conventions in operation at the time of death.

\section{COMPARATIVE DEATH RATES}

For some analyses we needed to compare the mortality of the Sellafield workforce with that of the general population of England and Wales. For this purpose the medical statistics division of the Office of Population Censuses and Surveys supplied us with a magnetic tape containing information by year on all deaths in England and Wales together with data on the population size. The data were supplied in five year age groupings (and for 85 years or older) by sex and by four digit ICD coding, using the ICD revision that was used for national statistics for each particular year. The ICD revisions used over the period of our study spanned the sixth to ninth revisions.

Because death rates in the general population vary in different parts of Britain we also tried to obtain data on the mortality of those in the same geographica region as Sellafield. For this purpose Professor M Gardner and Dr P Winte generously supplied us with the data for Cumberland that they had used for examining geographical variations in mortality in England and Wales during 1968 to $1978 .{ }^{112}$ These covered about 40000 deaths divided into 10 year age intervals (and 75 years and over) and into the cause of death groups used in their publications, together with a few additional causes.

\section{RADIATION DOSES}

Personal radiation dose records were kept for all workers at the Sellafield plant who other than infrequently entered areas where radiation exposure was possible ("controlled areas"). Doses were estimated from film badge dosimeters worn on the trunk. The aim was to maintain records on all those likely to enter such areas more than about once a year. Other workers who entered controlled areas would have been issued with a dosimeter but personal dose records were not maintained and we have no data on their exposures. British Nuclear Fuels estimates, however, that the maximum yearly dose to a worker from such exposure would be unlikely to exceed $0.8 \mathrm{mSv}(80 \mathrm{mrem})$ and usually the values would be very much lower. In this paper we have designated workers for whom British Nuclear Fuels maintained personal dose records as "radiation" workers and all others as "nonradiation" workers.

The number of dosimeters issued routinely to a radiation worker during a year varied according to the likelihood of radiation exposure and ranged typically from monthly to weekly.

For each radiation worker the whole body penetrating radiation dose in each year that the subject was monitored was estimated based on the individual dosimeter recordings. These data were supplied by British Nuclear Fuels for each worker, rounded to the nearest $0.1 \mathrm{mSv}(10 \mathrm{mrem})$. In addition, 128 workers had records of radiation exposures in employments other than at Sellafield. Those data were also supplied to us with doses attributed yearly where known.

No data on internal radiation exposure were supplied to us by British Nuclear Fuels, as we were informed that this information was not available in the company records in easily accessible form.

Of the 14000 workers of known age and sex included in the study, 3843 $(27 \cdot 5 \%)$ had no record of external radiation exposure. The remaining 10157 workers accumulated a total recorded exposure at Sellafield of $1259215 \mathrm{mSv}$ at some time during 1947 to 1983 , an average of $89.9 \mathrm{mSv}(9.0 \mathrm{rem})$ per worker or $124.0 \mathrm{mSv}(12.4 \mathrm{rem})$ per radiation worker. In addition, a total of $2578 \mathrm{mSv}$ were recorded as "transfer" doses - that is, doses received by workers in employments other than at Sellafield. Figure 1 shows the numbers of radiation workers in each year.

Figure 2 shows the distribution of total estimated doses accumulated while at Sellafield for those who were ever classified as radiation workers. In total 3469 workers $(34 \cdot 2 \%)$ accumulated doses of $100 \mathrm{mSv}(10 \mathrm{rem})$ or more, 542 $(5 \cdot 3 \%) 500 \mathrm{mSv}$ or more, and $48(0.5 \%) 1000 \mathrm{mSv}$ or more. The highest recorded accumulated dose was of $1759 \mathrm{mSv}(176 \mathrm{rem})$ in a man who had worked at Sellafield for 28 years. The highest dose recorded for any worker in a single year was $457 \mathrm{mSv}$ (46 rem).

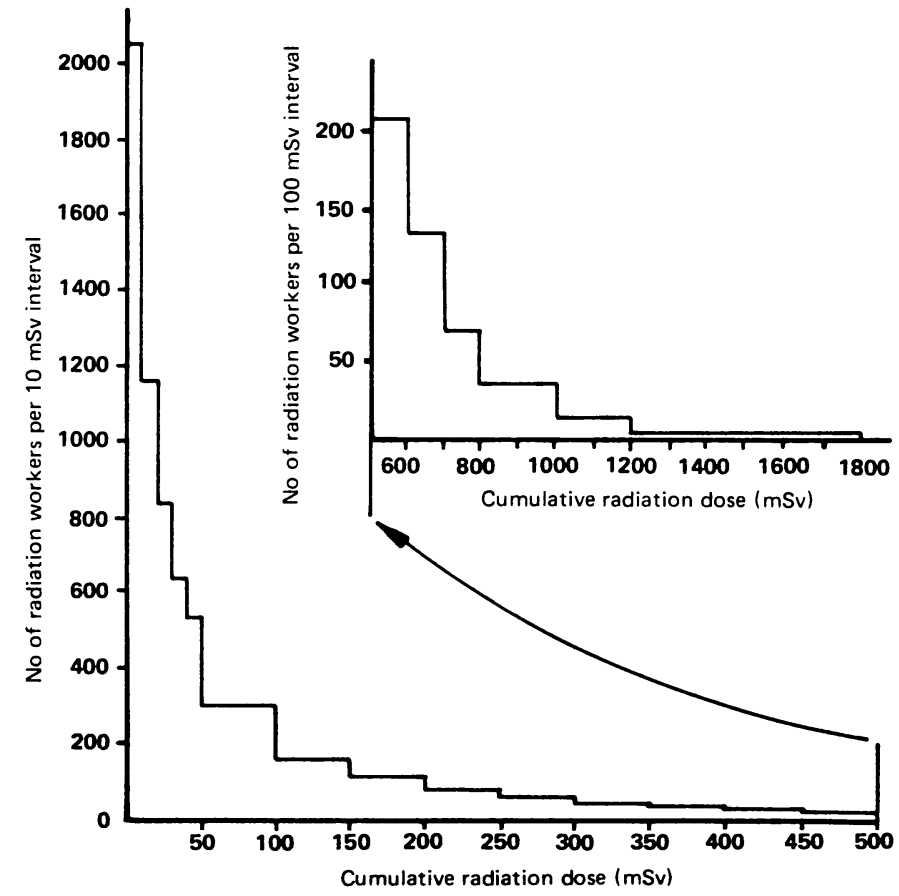

FIG 2-Distribution of measured radiation doses accumulated by Sellafield workers (men and women) during 1947 to 1983.

Conversion: SI to traditional units-Radiation dose: $10 \mathrm{mSv} \approx 1 \mathrm{rem}$.

Figure 3 shows the average radiation dose recorded for all current male and female workers and radiation workers in each year from 1947 to 1983 . From 1952 to 1969 the average yearly doses recorded for male radiation workers ranged from 8.7 to $20.2 \mathrm{mSv}(0.9$ to $2.0 \mathrm{rem})$ and for female radiation workers 2.6 to $8.4 \mathrm{mSv}$ $(0.3$ to $0.8 \mathrm{rem})$. Subsequently the recorded exposure levels fell progressively, such that by 1983 the average yearly exposures recorded were 7.0 and $1.6 \mathrm{mSv}$ $(0.7$ and $0.2 \mathrm{rem})$ for men and women respectively.

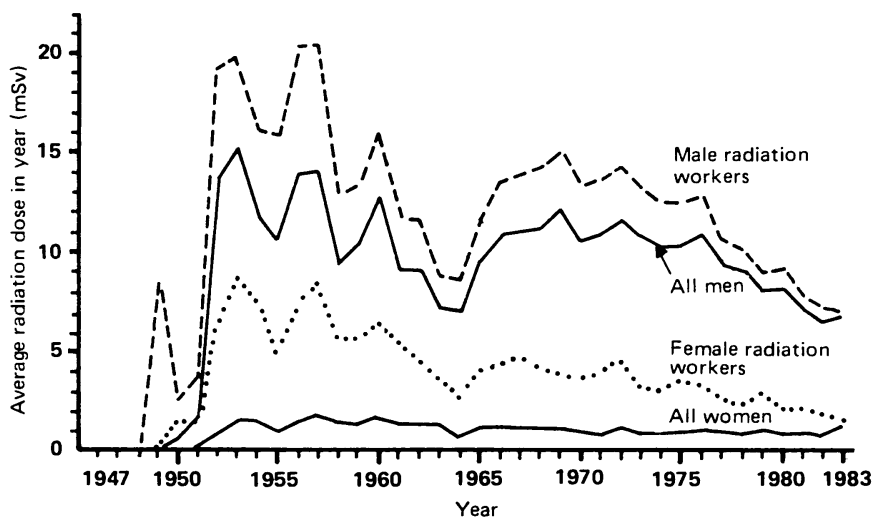

FIG 3-Average yearly radiation doses among radiation workers and among all workers.

Conversion: SI to traditional units—Radiation dose: $10 \mathrm{mSv} \approx 1 \mathrm{rem}$.

\section{STATISTICAL ANALYSIS}

Four different strategies of analysis were adopted. Firstly, to compare the mortality of the Sellafield workers with that of the general population of England and Wales the "expected" numbers of deaths in the Sellafield workers were estimated by multiplying the number of person years at risk during the study period by the corresponding national death rates for England and Wales. The numbers of years at risk were calculated separately for men and women for each five year age group up to 85 and for age 85 or more, and for each year from 1947 to 1983. Workers were regarded as having left the study. on the date of last emigration, death, or on the last date traced if any of these preceded 1 January 1984. Age specific death rates for the general population were computed for the corresponding periods from the data supplied by the Office of Population Censuses and Surveys and the years at risk in each age and year group were multiplied by these rates to give the numbers of deaths expected by cause.

Secondly, we compared the mortality of non-radiation workers with that of 
radiation workers. Workers were considered to be at risk in the first category until the year in which a personal dose record was started.

Thirdly, we wished to compare the death rates in the Sellafield workers with those of the population of Cumberland. We used the data from Professor Gardner and Dr Winter to calculate standardised mortality ratios from selected causes for Cumberland compared with England and Wales for 1968 to 1978. We then multiplied the yearly cause specific death rates in England and Wales by these ratios for 1947 to 1983 to derive an estimate of the Cumberland rates for this period, assuming that the standardised mortality ratios for 1968 and 1978 would be reasonably representative of those for the whole period. Where the total number of deaths from a particular cause in those aged 15 or more exceeded 300 in Cumberland for 1968 to 1978 we calculated the standardised mortality ratios in

TABLE I-Study population at 1 fanuary 1984

\begin{tabular}{lccc}
\hline & Men & Women & Total \\
\hline Total No (\%) of workers & $11604(100 \cdot 0)$ & $2633(100 \cdot 0)$ & $14327(100 \cdot 0)$ \\
No (\%) for whom date of birth or sex & $202(1 \cdot 7)$ & $35(1 \cdot 3)$ & $327 \star(2 \cdot 3)$ \\
not known & $11402(98 \cdot 3)$ & $2598(98 \cdot 7)$ & $14000(97 \cdot 7)$ \\
No (\%) submitted for tracing & $8450(72 \cdot 8)$ & $1992(75 \cdot 7)$ & $10442(72 \cdot 9)$ \\
Alive 1 January 1984 & $2048(17 \cdot 6)$ & $229(8 \cdot 7)$ & $2277(15 \cdot 9)$ \\
Died before 1984 & $344(3 \cdot 0)$ & $66(2 \cdot 5)$ & $410(2 \cdot 9)$ \\
Emigrated & $443(3 \cdot 8)$ & $200(7 \cdot 6)$ & $643(4 \cdot 5)$ \\
Incompletely traced & $117(1 \cdot 0)$ & $111(4 \cdot 2)$ & $228(1 \cdot 6)$ \\
Untraced & 245885 & 57662 & 303547 \\
Total years of follow up & $21 \cdot 6$ & $22 \cdot 2$ & $21 \cdot 7$ \\
Average duration of follow up (years) & & & \\
\hline
\end{tabular}

*Includes 80 of unknown sex and unknown date of birth and 10 of unknown sex but known date of birth. of 2277 deaths were recorded from all causes combined compared with 0 $2312 \cdot 1$ expected, giving a standardised mortality ratio of 98 . The numbers of deaths from all cancers and from other causes combined were also close to and not significantly different from the expected numbers. The findings were similar in $\varrho$ men and women.

There was a deficit of deaths in the first 10 years of the study period (1946-55; $\widehat{O}$ 56 observed, 94.6 expected; $p<0.001$ ) and a significant excess (standardised mortality ratio 113) in the period 1981-3 (table IIIm (miniprint)). Both the early deficit and the later excess were due mainly to deaths from causes other than $\mathbb{D}$ cancer. Standardised mortality ratios for deaths from cancer did not show statistically significant variations between the different periods, though there was TI a deficit of such deaths in the early years.

Table IVm shows the standardised mortality ratios by age at death. There was a deficit of deaths among those aged 25-44 (standardised mortality ratio (all causes) 73), most pronounced for causes other than cancers, and an excess of deaths 0 among those aged 65-84 (standardised mortality ratio (all causes) 108). The variation among the standardised mortality ratios for deaths due to cancer at $\frac{\bar{\sigma}}{\bar{n}}$ different ages was not statistically significant, nor did they show a significant $\frac{\mathrm{S}}{7}$ trend.

In the five years after first employment at Sellafield there was a substantial

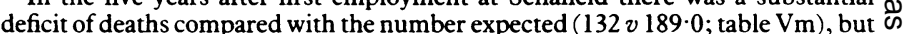
after this the standardised mortality ratios showed no consistent variation. There $\overrightarrow{0}$ was also a deficit of deaths from cancers in the first five year period ( 33 observed $v$. 43.6 expected), though this was not statistically significant. There was no $\overrightarrow{\vec{\omega}}$ consistent relation, however, between the duration of total employment at $\vec{\omega}$ Sellafield and mortality risk either for all causes combined or for all cancers (table $\mathrm{Vm}$ ). In particular, those employed for less than two years did not have an 3 overall mortality substantially different from that of those employed for longer periods.

Table VIm compares the mortality of radiation workers with that of other $\omega$ workers. For both men and women the standardised mortality ratio for deaths $\mathcal{G}$ from all causes was lower for radiation workers than for non-radiation workers of

TABLE II-Standardised mortality ratios $(S M R)$ for all causes of death and all cancers, by sex

\begin{tabular}{|c|c|c|c|c|c|c|c|}
\hline & \multicolumn{2}{|r|}{ Men } & \multicolumn{2}{|c|}{ Women } & \multicolumn{3}{|c|}{ Total } \\
\hline & SMR & No of deaths & SMR & No of deaths & No of deaths & Expected No & SMR \\
\hline All deaths & 98 & 2048 & 102 & 229 & 2277 & $2312 \cdot 13$ & 98 \\
\hline Deaths from cancers & 96 & 509 & 87 & 63 & 572 & $604 \cdot 38$ & 95 \\
\hline Deaths from other causes & 99 & 1539 & 109 & 166 & 1705 & $1707 \cdot 76$ & 100 \\
\hline
\end{tabular}

10 year age intervals (up to age 75 and for 75 years or more), but if the number of deaths was between 30 and 300 we calculated one standardised mortality ratio for all those aged 15 or more. Causes with fewer than 30 deaths were not considered in this way. We used these approximate rates for Cumberland to calculate expected deaths among the Sellafield workers in the same manner as above.

Fourthly, we examined the relation between recorded radiation dose and cause specific mortality among radiation workers by comparing death rates among workers who had accumulated different levels of exposure. Person years at risk for each worker were divided into different strata according to sex, age in five year age groups up to 85 , and for age 85 or more, employment state (industrial or nonindustrial), and calendar period in five year periods from 1945. Within each stratum a test for trend was conducted of the relation between deaths from specific causes and accumulated radiation dose (considered in the seven groups $0-, 10-, 20-, 50-, 100-, 200-$, and $\geqslant 400 \mathrm{mSv}$ ). The results from each stratum were added to provide a summary test for trend. The method used was the same as in similar studies. ${ }^{57}$ Because there were only a few deaths from some causes of interest statistical significance levels, usually based on the norma distribution, were checked in some cases by simulation experiments. In addition to examining the relation between mortality and accumulated radiation dose, analyses were conducted in which the radiation dose recordings were "lagged" by two and 15 years to allow for the possibility of an induction period between the radiation exposure and any excess mortality.

Our prior hypotheses were that workers who had been exposed to higher levels of radiation might be expected to show increased death rates from cancer. We had no grounds for believing that radiation exposure would protect against death from any cause. On this basis we considered that using one sided tests of statistical significance would be justified. For consistency, unless otherwise stated, all statistical significance tests presented are one sided in the direction of the observed difference or trend.

\section{Results}

\section{COMPARISON WITH DEATH RATES IN ENGLAND AND WALES AND IN} CUMBERLAND

The 14000 workers were followed up for a total of 303547 person years, an average of 21.7 years per person (table I). Table II shows the observed numbers of deaths among the Sellafield workers compared with the numbers that would have been expected on the basis of mortality data for England and Wales. A tota (standardised mortality ratios for both sexes combined 95 and 107 for the two groups respectively; $p<0.01$ ). Death rates from cancers, however, were similar in the two groups. For all causes and for all cancers death rates were higher in industrial workers than non-industrial workers but within each of these groups $\underline{0}$ the standardised mortality ratios for deaths from all causes were higher among $\supset$ non-radiation than radiation workers. Standardised mortality ratios were similar, $\supset$ however, for deaths from cancers among radiation and non-radiation workers.

Table VII shows the observed and expected deaths from cancers of different sites for radiation workers and non-radiation workers, and table VIIIm gives

\section{MINIPRINT TABLES III TO VI}
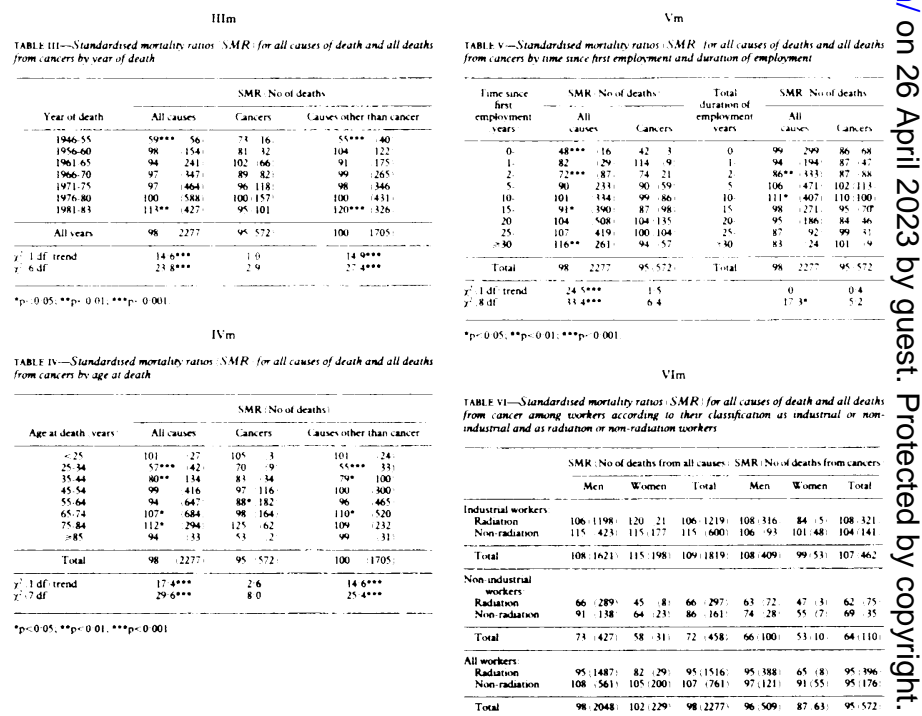
similar data for selected causes of death other than cancers. When comparisons were made with the numbers of deaths expected from national mortality data the observed number of deaths significantly exceeded the expected number for only one category of cancer site (ill defined and secondary neoplasms), and this was due mainly to an excess of deaths in this class among non-radiation workers. The only other statistically significant differences were deficits of liver and gall bladder cancer, lung cancer, and Hodgkin's disease among radiation workers and of leukaemia among non-radiation workers.

For causes of death other than cancers (table VIIIm) there were statistically significant deficits of deaths due to tuberculosis, all infective and parasitic conditions combined, all respiratory diseases combined, pneumonia, bronchitis, and all digestive diseases combined, while there were significant excesses of deaths from mental disorders, circulatory diseases, and ischaemic heart disease. For most non-neoplastic causes of death the standardised mortality ratios were ischaemic heart disease, was no longer present, reflecting the relatively high mortality from this cause in Cumberland compared with the rest of England and Wales. The deficit of deaths from pneumonia in the study group was also less pronounced when compared with the Cumberland rates.

Table IX shows the standardised mortality ratios for selected causes of death among radiation and non-radiation workers according to duration of employment at Sellafield. The division of the numbers in the table by duration of employment differs from that in table $\mathrm{Vm}$, as workers who became radiation workers at a date later than that of their first employment were initially included in the non radiation group and, subsequently, were classified according to their duration of work as a radiation worker. For radiation and non-radiation workers each cause of death was examined for evidence of a trend in the standardised mortality ratios with increasing duration of employment. The only statistically significant findings were of increasing standardised mortality ratios for stomach cancer

TABLE VII-Observed $(O)$ and expected $(E)$ deaths from specific cancers among radiation and other workers and standardised mortality ratios $(S M R)$

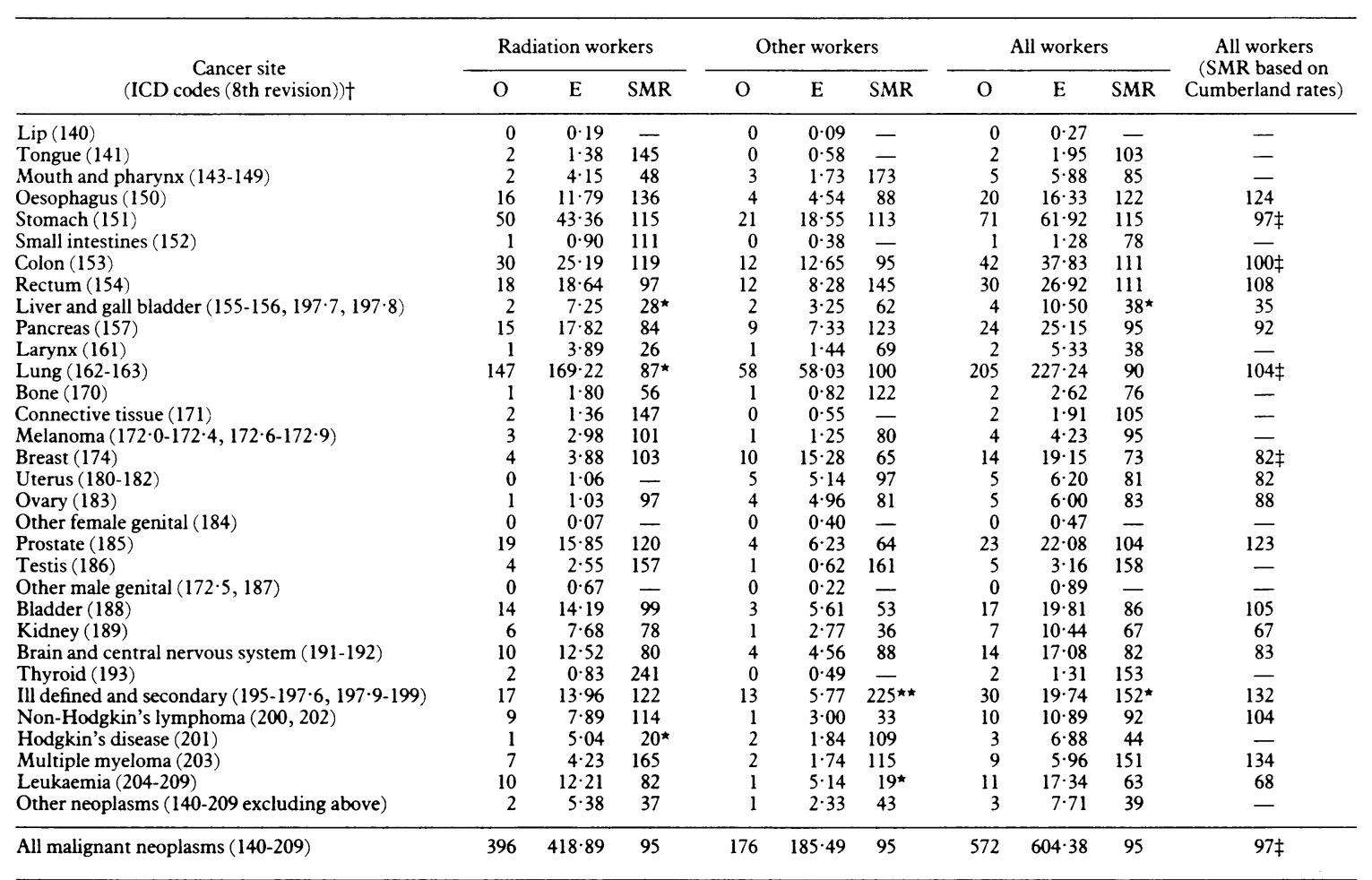

${ }^{\star} \mathrm{p}<0.05 ;{ }^{\star \star} \mathrm{p}<0.01 ;{ }^{\star \star \star} \mathrm{p}<0.001$.

IICD categories used for deaths occurring when 6 th, 7 th, or 9 th revision was in operation is available from authors.

†Age specific Cumberland SMRs estimated (for other causes shown, only overall SMRs for subjects aged 15 or more used to estimate Cumberland rates).

higher for non-radiation workers than for radiation workers. Exceptions were benign and unspecified neoplasms, cerebrovascular disease, influenza, all digestive diseases combined, peptic ulcer, and prostatic hyperplasia, but for none of these causes was the rate among radiation workers significantly higher than that among non-radiation workers.

To investigate to what extent the mortality of the Sellafield workers differed from that of the Cumberland population rather than that of England and Wales as a whole we also calculated, whenever possible (tables VII and VIIIm), the standardised mortality ratios for all workers based on the estimated Cumberland mortality data. There was some uncertainty in these comparisons as, firstly, we had available data from Cumberland for only part of the study period-that is, 1968 to 1978 (only about half of the deaths in the Sellafield population occurred in this period (table IIIm))-and, secondly, the ICD groupings used to estimate the Cumberland standardised mortality ratios were not in all instances identical with those used in the main analyses. Also age specific standardised mortality ratios for Cumberland could be calculated for only a restricted range of causes because of the small number of deaths in Cumberland from some causes.

For all causes of death combined the standardised mortality ratio for the Sellafield workers based on Cumberland rates was 91 (compared with 98 based on rates for England and Wales). Use of the Cumberland rates made little change to the standardised mortality ratio for all cancers combined or for cancers of most individual sites. The standardised mortality ratios were reduced for cancers of the stomach and colon and myeloma and cancers of ill defined and secondary sites, whereas those for cancers of the lung, breast, prostate, bladder, and for nonHodgkin's lymphoma were increased, but the only change that this made in tests of significance was that the excess of cancers of ill defined and secondary sites was no longer significant.

For causes of death other than cancer greater changes in standardised mortality ratios were produced by using estimated death rates for Cumberland. In particular, the excess of deaths from circulatory diseases, and especially among non-radiation workers and of decreasing standardised mortality ratios for accidents and violence among radiation workers - though for the latter group of causes the trend was similar for non-radiation workers. Neither for all causes of death combined nor for all cancers combined was there material evidence of a trend in the standardised mortality ratios with increasing duration of employment as a radiation or non-radiation worker.

\section{MINIPRINT TABLE VIII}

VIIIIm

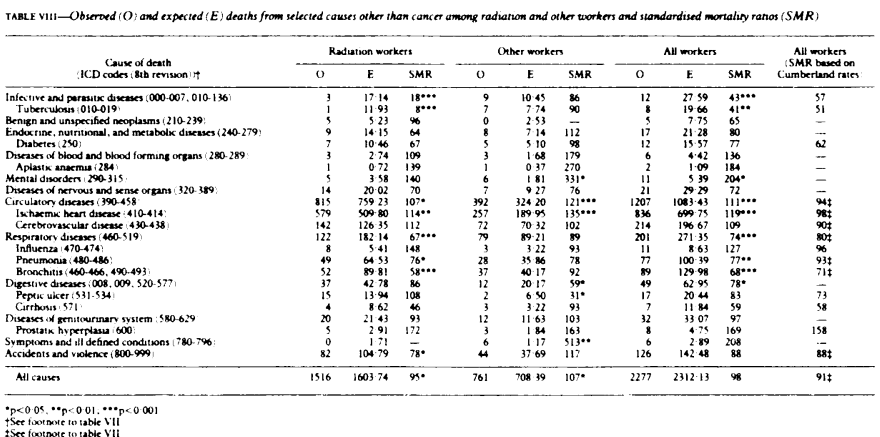


COMPARISON OF RADIATION WORKERS WITH DIFFERENT RECORDED LEVELS OF EXPOSURE

In addition to comparing the mortality of the Sellafield workers with that of the general population of England and Wales and of Cumberland, comparisons were made of the mortality of radiation workers who were recorded as having accumulated different levels of dose. Table $\mathrm{X}$ summarises these analyses for all malignant neoplasms combined and for cancers of those sites for which there were

TABLE IX-Standardised mortality ratios by duration of employment at Sellafield among radiation and other workers. (Figures in parentheses are observed numbers of deaths)

\begin{tabular}{|c|c|c|c|c|c|}
\hline \multirow{3}{*}{$\begin{array}{c}\text { Cause of death } \\
\text { (ICD codes (8th revision)) } \\
\text { Carcinoma stomach (151) }\end{array}$} & \multirow{3}{*}{$\frac{\begin{array}{c}\text { Radiation } \\
\text { worker }\end{array}}{\left\{\begin{array}{l}\text { No } \\
\text { Yes }\end{array}\right.}$} & \multicolumn{3}{|c|}{ Duration of employment (years) } & \multirow{3}{*}{$\frac{(1 \mathrm{df} \text { trend })}{\chi^{2}}$} \\
\hline & & $<2$ & $2-9$ & $\geqslant 10$ & \\
\hline & & $\begin{array}{ll}89 & (7) \\
96 & (6)\end{array}$ & $\begin{array}{rr}70 & (5) \\
128 & (21)\end{array}$ & $\begin{array}{lr}256 & (9) \\
111 & (23)\end{array}$ & \\
\hline Carcinoma colon (153) & $\begin{array}{l}\text { No } \\
\text { Yes }\end{array}$ & $\begin{array}{ll}103 & (6) \\
108 & (4)\end{array}$ & $\begin{array}{ll}66 & (3) \\
75 & (7)\end{array}$ & $\begin{array}{lr}131 & (3) \\
156 & (19)\end{array}$ & $\begin{array}{l}0.02 \\
1.56\end{array}$ \\
\hline Carcinoma pancreas (157) & $\begin{array}{l}\text { No } \\
\text { Yes }\end{array}$ & $\begin{array}{ll}152 & (5) \\
120 & (3)\end{array}$ & $\begin{array}{ll}152 & (4) \\
110 & (7)\end{array}$ & $\begin{array}{rr}0 & (0) \\
56 & (5)\end{array}$ & $\begin{array}{l}1 \cdot 40 \\
1.52\end{array}$ \\
\hline Carcinoma lung (162-163) & $\begin{array}{l}\text { No } \\
\text { Yes }\end{array}$ & $\begin{aligned} 119 & (29) \\
43 & (10)\end{aligned}$ & $\begin{aligned} & 88(19) \\
& 117(70)\end{aligned}$ & $\begin{array}{ll}83 & (10) \\
78 & (67)\end{array}$ & $\begin{array}{l}1 \cdot 31 \\
0.09\end{array}$ \\
\hline Carcinoma prostate (185) & $\begin{array}{l}\text { No } \\
\text { Yes }\end{array}$ & $\begin{array}{ll}102 & (2) \\
117 & (2)\end{array}$ & $\begin{array}{rr}40 & (1) \\
168 & (9)\end{array}$ & $\begin{array}{ll}58 & (1) \\
91 & (8)\end{array}$ & $\begin{array}{l}0 \cdot 30 \\
0 \cdot 70\end{array}$ \\
\hline $\begin{array}{l}\text { Ill defined and secondary } \\
\text { cancers }(195-197 \cdot 6 \text {, } \\
197 \cdot 9-199)\end{array}$ & $\begin{array}{l}\text { No } \\
\text { Yes }\end{array}$ & $\begin{array}{ll}182 & (5) \\
254 & (5)\end{array}$ & $\begin{array}{rr}206 & (4) \\
85 & (4)\end{array}$ & $\begin{array}{ll}367 & (4) \\
110 & (8)\end{array}$ & $\begin{array}{l}0.98 \\
1.39\end{array}$ \\
\hline Multiple myeloma (203) & $\begin{array}{l}\text { No } \\
\text { Yes }\end{array}$ & $\begin{array}{rr}123 & (1) \\
0 & (0)\end{array}$ & $\begin{array}{rr}0 & (0) \\
270 & (4)\end{array}$ & $\begin{array}{ll}313 & (1) \\
139 & (3)\end{array}$ & $\begin{array}{l}0.28 \\
0.05\end{array}$ \\
\hline Leukaemia (204-209) & $\begin{array}{l}\text { No } \\
\text { Yes }\end{array}$ & $\begin{array}{rr}0 & (0) \\
44 & (1)\end{array}$ & $\begin{array}{ll}57 & (1) \\
61 & (3)\end{array}$ & $\begin{array}{rr}0 & (0) \\
119 & (6)\end{array}$ & $\begin{array}{l}0 \cdot 23 \\
1 \cdot 35\end{array}$ \\
\hline $\begin{array}{l}\text { All malignant } \\
\text { neoplasms }(140-209)\end{array}$ & $\begin{array}{l}\text { No } \\
\text { Yes }\end{array}$ & $\begin{array}{ll}96 & (81) \\
73 & (45)\end{array}$ & $\begin{array}{r}85(57) \\
107(165)\end{array}$ & $\begin{array}{r}112(38) \\
92(186)\end{array}$ & $\begin{array}{l}0 \cdot 28 \\
0 \cdot 29\end{array}$ \\
\hline $\begin{array}{l}\text { Circulatory diseases } \\
(390-458)\end{array}$ & $\begin{array}{l}\text { No } \\
\text { Yes }\end{array}$ & $\begin{array}{r}118(163) \\
91(95)\end{array}$ & $\begin{array}{l}126(151) \\
110(307)\end{array}$ & $\begin{array}{l}119(78) \\
110(413)\end{array}$ & $\begin{array}{l}0.04 \\
1 \cdot 75\end{array}$ \\
\hline $\begin{array}{l}\text { Ischaemic heart disease } \\
\quad(410-414)\end{array}$ & $\begin{array}{l}\text { No } \\
\text { Yes }\end{array}$ & $\begin{array}{r}136(110) \\
89(63)\end{array}$ & $\begin{array}{l}132(92) \\
117(214)\end{array}$ & $\begin{array}{l}141(55) \\
118(302)\end{array}$ & $\begin{array}{l}0.03 \\
2 \cdot 70\end{array}$ \\
\hline $\begin{array}{l}\text { Cerebrovascular disease } \\
\quad(430-438)\end{array}$ & $\begin{array}{l}\text { No } \\
\text { Yes }\end{array}$ & $\begin{array}{ll}102 & (30) \\
126 & (21)\end{array}$ & $\begin{array}{ll}117 & (31) \\
106 & (51)\end{array}$ & $\begin{array}{r}77(11) \\
114(70)\end{array}$ & $\begin{array}{l}0.31 \\
0.03\end{array}$ \\
\hline $\begin{array}{l}\text { Respiratory diseases } \\
(\mathbf{4 6 0 - 5 1 9 )}\end{array}$ & $\begin{array}{l}\text { No } \\
\text { Yes }\end{array}$ & $\begin{array}{ll}83 & (29) \\
91 & (22)\end{array}$ & $\begin{array}{ll}98 & (34) \\
66 & (46)\end{array}$ & $\begin{array}{ll}81(16) \\
61(54)\end{array}$ & $\begin{array}{l}0.01 \\
2.01\end{array}$ \\
\hline $\begin{array}{l}\text { Digestive diseases } \\
\quad(008,009,520-577)\end{array}$ & $\left\{\begin{array}{l}\text { No } \\
\text { Yes }\end{array}\right.$ & $\begin{array}{ll}75 & (7) \\
70 & (5)\end{array}$ & $\begin{array}{rr}40 & (3) \\
118 & (20)\end{array}$ & $\begin{array}{rr}59 & (2) \\
64 & (12)\end{array}$ & $\begin{array}{l}0.32 \\
0.47\end{array}$ \\
\hline $\begin{array}{l}\text { Accidents and violence } \\
\quad(800-999)\end{array}$ & $\left\{\begin{array}{l}\text { No } \\
\text { Yes }\end{array}\right.$ & $\begin{array}{ll}131 & (29) \\
111 & (30)\end{array}$ & $\begin{aligned} 109 & (13) \\
74 & (36)\end{aligned}$ & $\begin{array}{ll}55 & (2) \\
55 & (16)\end{array}$ & $\begin{array}{l}1 \cdot 51 \\
5 \cdot 66^{\star \star}\end{array}$ \\
\hline All causes & $\begin{array}{l}\text { No } \\
\text { Yes }\end{array}$ & $\begin{array}{r}105(330) \\
87(211)\end{array}$ & $\begin{array}{r}109(282) \\
98(596)\end{array}$ & $\begin{array}{r}112(149) \\
94(709)\end{array}$ & $\begin{array}{l}0.49 \\
0.40\end{array}$ \\
\hline
\end{tabular}

${ }^{\star} \mathrm{p}<0.05 ;{ }^{\star \star} \mathrm{p}<0.01$. five or more deaths among radiation workers. For no site for which there were $\square$ fewer than five deaths was there any indication of a definite association between accumulated radiation dose and cancer risk. Table XI shows similar analyses for all causes combined and for selected causes of death other than malignant neoplasms.

For all causes of death combined (table XI) there was a significant $(p<0.05) \widehat{\triangle}$ negative association between mortality risk and accumulated radiation dose. $\overline{\bar{J}}$ Radiation workers who had accumulated higher radiation doses tended to have lower death rates than workers with smaller accumulated doses. Such a trend was $\mathbb{D}$ most pronounced for all malignant neoplasms combined (table $\mathrm{X}$ ) and was $\Pi$ diseases there was little evidence of such a trend for pneumonia (49 deaths) or 2 influenza (eight deaths) but a pronounced trend for deaths from bronchitis (52 deaths: $\mathrm{z}$ statistic $=-2.21 ; \mathrm{p}<0.05($ not shown in table $\mathrm{X})$ ). For deaths from cancers of individual sites there was no statistically significant association $\square$ between mortality risk and accumulated radiation dose, though there was a non-significant positive association for deaths from leukaemia (table $\mathrm{X}$ ).

Tables X and XI also show the distributions of observed and expected deaths $\frac{\bar{\rho}}{\bar{D}}$ that related to the radiation dose accumulated up to the time of death. Because it $\mathbb{D}$ may not be until several years after exposure that a radiation dose produces an increased mortality risk, we also conducted analyses in which the recorded yearly radiation doses were "lagged" by two and 15 years-that is, we related the $\vec{\nabla}$ mortality risk at a given time to the radiation dose that had been accumulated up to two (or 15) years previously and ignored any subsequent exposure. The values $\overrightarrow{\vec{\omega}}$ of the test statistic ( $\mathrm{z}$ ) for a trend between accumulated dose and mortality risk with these lag periods are also presented in tables X and XI. With a lag of two years there remained a significant negative association between accumulated dose and deaths from all causes combined, but none of the other associations between mortality risk and radiation dose were statistically significant. With a lag of 15 years the negative association with deaths from all causes was no longer apparent. With the 15 year lag, however, there were high $\mathrm{z}$ values, giving a measure of the associations between radiation dose and mortality from bladder or cancer, myeloma, and leukaemia and for all lymphatic and haematopoietic. neoplasms combined. Table XII give the data for these causes in more detail. Because of the comparatively small number of deaths from these cancers in radiation workers the statistical significance of the tests for trend was evaluated by simulation experiments. These showed that, with the exception of leukaemia, the associations were significant at the $5 \%$ level. Table XII also shows the expected numbers of deaths, assuming the workers in each dose category to have the same death rates as the general population of England and Wales. In general the trends in the ratios of observed to expected deaths with increasing dose were similar whether the comparisons between groups were based on "internal" analyses or on mortality data for England and Wales, though the associations for bladder cancer and for all malignant neoplasms were stronger when the comparisons were with ates for England and Wales.

The numbers of deaths from leukaemia, myeloma, and cancer of the bladder (table XII) were too small to obtain reasonable separate estimates of the relations between the excess mortality risks and the accumulated radiation doses. Such an estimate was made, however, for all malignant neoplasms combined, using the data shown in table XII. The differences between the observed and expected numbers of deaths in each dose category based on the "internal" analyses were divided by the total person years at risk in each dose category and a linear doseresponse relation fitted to relate the excess mortality rates to accumulated radiation dose. The maximum likelihood estimate of the excess risk associated with an increment in dose of $10 \mathrm{mSv}(1 \mathrm{rem})$ was 17 per million person years at risk 15 or more years after exposure with approximate $95 \%$ confidence limits of -30 and 70 . The corresponding estimates based on the data in table $\mathrm{X}$, in which

TABLE X-Deaths from selected cancers among radiation workers by cumulative radiation exposure (adjusted for age, sex, calendar period, and industrial state). (Figures in parentheses are expected distribution of deaths assuming no relation between dose and cancer risk.) Data in body of table are for analysis including no lag period

\begin{tabular}{|c|c|c|c|c|c|c|c|c|c|c|c|}
\hline \multirow{2}{*}{$\begin{array}{c}\text { Cancer site } \\
\text { (ICD codes ( } 8 \text { th revision)) }\end{array}$} & \multicolumn{7}{|c|}{ Radiation dose monitored (mSv) } & \multirow{2}{*}{$\begin{array}{l}\text { Total } \\
\text { deaths }\end{array}$} & \multicolumn{3}{|c|}{$\begin{array}{l}z \text { Test for trend. } \dagger \\
\text { Lag of radiation dose (years): }\end{array}$} \\
\hline & $<10$ & 10 & 20 & $50-$ & 100 & 200 & $\geqslant 400$ & & 0 & 2 & 15 \\
\hline Oesophagus (150) & $1(2 \cdot 0)$ & $0(1 \cdot 2)$ & $4(3 \cdot 1)$ & $4(2 \cdot 8)$ & $0(2 \cdot 5)$ & $7(2 \cdot 7)$ & $0(1 \cdot 8)$ & 16 & $-0 \cdot 12$ & -0.38 & -0.25 \\
\hline Stomach (151) & $9(8.0)$ & $5(4 \cdot 3)$ & $5(9 \cdot 2)$ & $14(9 \cdot 4)$ & $5(8.0)$ & $7(6 \cdot 8)$ & $5(4 \cdot 4)$ & 50 & $0 \cdot 18$ & 0.22 & -0.80 \\
\hline Colon (153) & $7(4 \cdot 7)$ & $3(2.5)$ & $4(5.4)$ & $6(5 \cdot 1)$ & $5(4 \cdot 7)$ & $4(4 \cdot 3)$ & $1(3 \cdot 3)$ & 30 & -1.44 & $-1 \cdot 37$ & $-1 \cdot 38$ \\
\hline Rectum (154) & $3(2 \cdot 4)$ & $0(1.4)$ & $4(3.0)$ & $3(2.9)$ & $2(3.0)$ & $3(2 \cdot 8)$ & $3(2 \cdot 4)$ & 18 & 0.40 & 0.55 & 0.63 \\
\hline Pancreas (157) & $3(2 \cdot 0)$ & $3(1.4)$ & $3(2.5)$ & $1(2 \cdot 1)$ & $1(2 \cdot 3)$ & $2(2 \cdot 6)$ & $2(2 \cdot 1)$ & 15 & -0.63 & -0.56 & 0.49 \\
\hline Lung (162-163) & $22(22 \cdot 8)$ & $5(12 \cdot 3)$ & $32(26 \cdot 1)$ & $32(24 \cdot 0)$ & $23(23 \cdot 3)$ & $18(22 \cdot 6)$ & $15(16.0)$ & 147 & -0.60 & -0.60 & 0.56 \\
\hline Prostate (185) & $3(3 \cdot 3)$ & $2(1.5)$ & $2(3 \cdot 3)$ & $4(3 \cdot 3)$ & $3(2.9)$ & $5(2 \cdot 6)$ & $0(2 \cdot 2)$ & 19 & -0.76 & -0.65 & -0.48 \\
\hline Bladder (188) & $0(1 \cdot 7)$ & $1(0.9)$ & $3(2 \cdot 2)$ & $2(2 \cdot 2)$ & $1(2 \cdot 4)$ & $4(2 \cdot 6)$ & $3(1.9)$ & 14 & $1 \cdot 20$ & $1 \cdot 27$ & $2 \cdot 13^{\star}$ \\
\hline Kidney (189) & $1(0 \cdot 7)$ & $0(0.5)$ & $1(1.0)$ & $3(0.8)$ & $0(1.0)$ & $1(1 \cdot 1)$ & $0(0.8)$ & 6 & $-1 \cdot 12$ & -1.02 & -1.04 \\
\hline Brain and central nervous system (191-192) & $1(1.8)$ & $1(1 \cdot 1)$ & $2(2 \cdot 2)$ & $2(1 \cdot 3)$ & $2(1.5)$ & $1(1 \cdot 3)$ & $1(0.9)$ & 10 & $0 \cdot 18$ & 0.34 & 0.92 \\
\hline Ill defined and secondary $(195-197 \cdot 6,197 \cdot 9-199)$ & $3(3 \cdot 3)$ & $0(1 \cdot 6)$ & $4(3 \cdot 4)$ & $3(2 \cdot 5)$ & $3(2 \cdot 4)$ & $3(2 \cdot 3)$ & $1(1 \cdot 4)$ & 17 & 0.09 & $0 \cdot 25$ & 0.93 \\
\hline Non-Hodgkin's lymphoma $(200,202)$ & $2(1 \cdot 2)$ & $2(0 \cdot 7)$ & $2(1.5)$ & $0(1 \cdot 6)$ & $1(1.5)$ & $1(1 \cdot 4)$ & $1(1 \cdot 1)$ & 9 & -0.64 & -0.54 & $-0 \cdot 22$ \\
\hline Multiple myeloma (203) & $0(1 \cdot 0)$ & $0(0.6)$ & $2(1 \cdot 3)$ & $2(1 \cdot 1)$ & $1(1 \cdot 0)$ & $0(1 \cdot 1)$ & $2(0.9)$ & 7 & 0.89 & $1 \cdot 05$ & $2 \cdot 66^{\star}$ \\
\hline Leukaemia (204-209) & $2(1 \cdot 7)$ & $1(1 \cdot 2)$ & $1(2 \cdot 1)$ & $1(1 \cdot 7)$ & $2(1 \cdot 6)$ & $1(1 \cdot 2)$ & $2(0 \cdot 7)$ & 10 & 1.52 & 1.01 & $1 \cdot 76^{\star}$ \\
\hline All lymphatic and haematopoietic (200-209) & $5(4 \cdot 0)$ & $3(2 \cdot 7)$ & $5(5 \cdot 1)$ & $3(4 \cdot 5)$ & $4(4 \cdot 2)$ & $2(3 \cdot 8)$ & $5(2 \cdot 8)$ & 27 & $0 \cdot 78$ & 0.66 & $2 \cdot 04^{\star}$ \\
\hline All malignant neoplasms (140-209) & $54(62 \cdot 9)$ & $27(34 \cdot 4)$ & $4(72 \cdot 3)$ & $82(65 \cdot 0)$ & $54(61 \cdot 5)$ & $59(58 \cdot 2)$ & $36(41 \cdot 8)$ & 396 & -0.92 & $-0 \cdot 78$ & $0 \cdot 72$ \\
\hline
\end{tabular}

${ }^{\star} \mathrm{p}<0.05$.

†Based on mean doses in each dose category according to person years at risk at different dose levels. Means were: for 0 lag $4 \cdot 2,14 \cdot 7,33 \cdot 1,71 \cdot 9,142 \cdot 2,279 \cdot 2$, and $579 \cdot 2 \mathrm{mSv}$; for 2 year lag $2 \cdot 9$, $14 \cdot 7,33 \cdot 1,71 \cdot 9,142 \cdot 1,278 \cdot 4$, and $572 \cdot 1 \mathrm{mSv}$; for 15 year lag $0 \cdot 6,14 \cdot 6,33 \cdot 1,71 \cdot 8,141 \cdot 3,271 \cdot 8$, and $516 \cdot 7 \mathrm{mSv}$. Computations were also conducted using median doses in each dose category but results were not materially affected.

Conversion: SI to traditional units-Radiation dose: $10 \mathrm{mSv} \approx 1 \mathrm{rem}$ 
TABLE XI-Deaths from selected non-malignant causes among radiation workers by cumulative radiation exposure (adjusted for age, sex, calendar period, and industrial state). (Figures in parentheses are expected distribution of deaths assuming no relation between dose and mortality risk.) Data in body of table are for analysis including no lag period

\begin{tabular}{|c|c|c|c|c|c|c|c|c|c|c|c|}
\hline \multirow{2}{*}{$\begin{array}{c}\text { Cause of death } \\
\text { (ICD codes ( } 8 \text { th revision)) }\end{array}$} & \multicolumn{7}{|c|}{ Radiation dose monitored (mSv) } & \multirow{2}{*}{$\begin{array}{l}\text { Total } \\
\text { deaths }\end{array}$} & \multicolumn{3}{|c|}{$\begin{array}{c}\text { z Test for trend. } \dagger \\
\text { Lag of radiation dose (years): }\end{array}$} \\
\hline & $<10$ & 10 & 20 & $50-$ & 100 & $200-$ & $\geqslant 400$ & & 0 & 2 & 15 \\
\hline $\begin{array}{l}\text { Circulatory diseases }(390-458) \\
\text { Ischaemic heart disease }(410-414) \\
\text { Cerebrovascular disease }(430-438) \\
\text { Respiratory diseases }(460-519) \\
\text { Digestive diseases }(008,009,520-577) \\
\text { Genitourinary diseases }(580-629) \\
\text { Accidents and violence }(800-999)\end{array}$ & $\begin{array}{rr}129 & (128 \cdot 4) \\
93 & (88 \cdot 5) \\
21 & (23 \cdot 9) \\
28 & (19 \cdot 8) \\
9 & (6 \cdot 4) \\
4 & (3 \cdot 2) \\
23 & (19 \cdot 0)\end{array}$ & $\begin{array}{rr}82 & (70 \cdot 6) \\
58 & (50 \cdot 7) \\
14 & (11 \cdot 6) \\
12 & (9 \cdot 0) \\
3 & (3 \cdot 4) \\
2 & (1 \cdot 8) \\
7 & (9 \cdot 2)\end{array}$ & $\begin{aligned} 156 & (149 \cdot 0) \\
107 & (103 \cdot 8) \\
23 & (26 \cdot 8) \\
27 & (22 \cdot 2) \\
6 & (7 \cdot 7) \\
4 & (3 \cdot 7) \\
18 & (16 \cdot 7)\end{aligned}$ & $\begin{array}{rr}128 & (138 \cdot 8) \\
83 & (97 \cdot 7) \\
29 & (24 \cdot 6) \\
12 & (21 \cdot 6) \\
8 & (6 \cdot 5) \\
5 & (3 \cdot 4) \\
11 & (12 \cdot 6)\end{array}$ & $\begin{array}{rr}122 & (127 \cdot 9) \\
87 & (92 \cdot 1) \\
25 & (21 \cdot 3) \\
19 & (19 \cdot 5) \\
6 & (5 \cdot 6) \\
1 & (3 \cdot 2) \\
11 & (11 \cdot 2)\end{array}$ & $\begin{aligned} 123 & (118 \cdot 8) \\
97 & (86 \cdot 6) \\
13 & (20 \cdot 1) \\
15 & (17 \cdot 6) \\
3 & (4 \cdot 6) \\
2 & (2 \cdot 8) \\
9 & (8 \cdot 6)\end{aligned}$ & $\begin{array}{rr}75 & (81 \cdot 6) \\
54 & (59 \cdot 5) \\
17 & (13 \cdot 7) \\
9 & (12 \cdot 3) \\
2 & (2 \cdot 8) \\
2 & (2 \cdot 0) \\
3 & (4 \cdot 8)\end{array}$ & $\begin{array}{r}815 \\
579 \\
142 \\
122 \\
37 \\
20 \\
82\end{array}$ & $\begin{array}{l}-0 \cdot 82 \\
-0 \cdot 46 \\
0 \cdot 35 \\
-1 \cdot 76^{\star} \\
-0 \cdot 90 \\
-0 \cdot 51 \\
-0.87\end{array}$ & $\begin{array}{r}-0 \cdot 55 \\
-0 \cdot 14 \\
0 \cdot 30 \\
-1 \cdot 50 \\
-0 \cdot 71 \\
-0 \cdot 33 \\
-0 \cdot 49\end{array}$ & $\begin{array}{r}0 \cdot 68 \\
0 \cdot 40 \\
0 \cdot 76 \\
0 \cdot 16 \\
-0 \cdot 93 \\
0 \cdot 27 \\
-0 \cdot 05\end{array}$ \\
\hline All causes & $266(247 \cdot 3)$ & $139(132 \cdot 6)$ & $293(279 \cdot 4)$ & $254(255 \cdot 0)$ & $220(235 \cdot 6)$ & $215(216 \cdot 6)$ & $129(149 \cdot 5)$ & 1516 & $-2 \cdot 22^{\star}$ & $-1 \cdot 75^{\star}$ & $0 \cdot 72$ \\
\hline Person years at risk & 49417 & 26067 & 44532 & 31898 & 28248 & 20159 & 10042 & 210362 & & & \\
\hline
\end{tabular}

${ }^{\star} \mathrm{p}<0.05$.

† See footnote to table $\mathrm{X}$.

Conversion: SI to traditional units-Radiation dose: $10 \mathrm{mSv} \approx 1 \mathrm{rem}$.

the radiation doses were not lagged, was -6 per million person years at risk per $10 \mathrm{mSv}$ - that is, a reduction of 6 per million person years at risk per $10 \mathrm{mSv}$ with approximate $95 \%$ confidence limits of -23 and 12 .

The analyses in tables X and XI were repeated with an additional stratification in the analysis for time since first employment at Sellafield (in the seven groups 0$5-, 10-, 15-, 20-, 25-$, and $\geqslant 30$ years). This made little difference to the findings, however. The $\mathrm{z}$ values for the trend test for all causes and all neoplasms were: 0 lag, -2.75 and -0.85 (compared with -2.22 and -0.92 , respectively, in tables XI and X); 15 year lag, 0.06 and 0.72 (compared with 0.72 and 0.72 , respectively).

\section{Discussion}

\section{COMPLETENESS OF ASCERTAINMENT OF STUDY POPULATION AND} DEATHS

We have attempted to study the mortality of all people who have ever been employed at the Sellafield nuclear reprocessing plant of British Nuclear Fuels since it opened in 1947. In a retrospective cohort study of this kind it is important to ensure that the ascertainment of the study population and of deaths in that population is as complete as possible so as to minimise the possibility of bias in the results. This is especially the case in a setting in which the employer has been largely responsible for assembling the data for analysis. In our study it was possible to do this in several ways.

We were able to check that we were supplied with data associated with a very high proportion of the consecutive works numbers that had been issued from the time the plant opened to 31 December 1975. An additional 305 workers were identified by British Nuclear Fuels who appeared not to have been issued with a number, most of whom were employed before 1953 for less than three years. Possibly other workers may have been wrongly excluded from the study population, but it seemed reasonable to assume that a very high proportion of the workforce had been identified.

Deaths in the workforce were ascertained through two independent sources-the NHS Central Register and the national insurance records branch of the DHSS. By combining the information from these two sources $96.1 \%$ of the workers were traced (table I). Furthermore, the trace data, including copies of death certificates, supplied by the central register and the records branch were transmitted directly to us before being forwarded to British Nuclear Fuels.

The possibility remained, however, that British Nuclear Fuels might have failed to identify some workers and not submitted them for tracing. It was not possible to check this directly, but we conducted an indirect check. We noticed that a high proportion of the death certificates for workers in the study either included mention of British Nuclear Fuels or used the words "nuclear" or "atomic energy" in the description of occupation. Sellafield is the only atomic energy establishment in south Cumbria. Dr P Tiplady, of the East Cumbrian Health Authority, kindly gave us access to the death certificates for the period 1959 to 1980 for deaths registered by the Whitehaven or Millom registrars (the two registrars closest to the Sellafield plant). Examination of these identified 726 certificates mentioning a "nuclear" occupation. We were able to trace $705(97 \cdot 1 \%)$ of these people in the study population (among the 1711 deaths we had recorded for British Nuclear Fuels workers in the period 1959 to 1980), and for all but two of these we had a record of the death. In the remaining 21 instances we could find no record of the subjects in the study population. Possibly some of the death certificates had the occupation wrongly recorded or the occupation described related to a site other than Sellafield, and a few subjects may have been first employed at Sellafield after 1975. Among the 23 deaths for which we had no record, only two were due to cancer (of the lung and kidney). Thus this independent check confirmed a reasonably complete ascertainment of the study population and of deaths within it.

\section{DOSIMETRY}

While we were able to perform some monitoring and checks on the completeness of the mortality data that were supplied to us, this was not possible for the data on estimated radiation doses to workers, which were supplied by British Nuclear Fuels on computer tape. We therefore approached the National Radiological Protection Board to ask if it would be possible for its staff to check a random sample of the radiation records that had been supplied. The board kindly agreed and we selected a stratified random sample of workers for such checking. We included most workers who had died from lymphatic or haematopoietic neoplasms and samples of roughly 20 workers recorded as having accumulated radiation doses of less than $50 \mathrm{mSv}, 50-99 \cdot 9 \mathrm{mSv}, 100-199 \cdot 9 \mathrm{mSv}, 200-499 \cdot 9 \mathrm{mSv}$, and $500 \mathrm{mSv}$ or more. The results of the checks conducted by the board will be published elsewhere (G M Kendall et al, paper in preparation).

In summary, before 1969 dose records at Sellafield were maintained manually. In 1969 a computerised record system was introduced. Of the sample of 123 subjects supplied to the National Radiological Protection Board, four with no doses were included and it was confirmed that no dose records were held at Sellafield. The remaining 119 workers had been monitored for a total of 1531 years and, on average, had been issued with 20 dosimeters a year (range four to over 50 ). There were several instances in which the yearly total dose for a subject as supplied to us by British Nuclear Fuels did not agree with the total computed by the National Radiological Protection Board. In many cases these discrepancies were trivial and may have been due to different conventions for rounding doses. In 18 instances the error in a yearly dose was greater than $5 \%$. The largest error was an overestimate of $25.6 \mathrm{mSv}(2 \cdot 7 \mathrm{rem})$ in a yearly dose supplied as $67.5 \mathrm{mSv}$ $(6.8 \mathrm{rem})$. The largest underestimate of dose was a total recorded as $38.3 \mathrm{mSv}(3.8 \mathrm{rem})$, which should have been $54.2 \mathrm{mSv}(5.4 \mathrm{rem})$. The errors were both positive and negative, and for the 18 yearly totals combined the recorded dose was $518.6 \mathrm{mSv}(51.9 \mathrm{rem})$, whereas the true total should have been $523.1 \mathrm{mSv}(52.3 \mathrm{rem})$. Discrepancies of this order are unlikely to have had great effect on interpretation of the analyses presented here.

If a dosimeter was lost or there was a fault in processing, an estimated dose or "pro rata" dose was recorded. Estimated doses were based on the worker's usual level of exposure; $0.8 \%$ of dose assessments-that is, accounting for less than $2 \%$ of the total dose-were so recorded. A few doses were recorded as "pro rata notional doses" (for which a dose was assigned as the fraction of the yearly permissible dose limit for the period during which the missing dosimeter was worn); such doses accounted for less than $1 \%$ of the total collective dose.

The introduction of the computerised record system allowed information on special features of the dose assessment to be stored more easily. After 1968 about one fifth of dosimeters in the sample were recorded as "contaminated" (compared with $0.6 \%$ before 1969), indicating that radioactive particles had landed directly on the film badge. It is believed that the proportion of contaminated dosimeters was higher in this stratified sample than in the workforce as a whole, for whom British Nuclear Fuels have reported about $6 \%$ contaminated dosimeters in recent years. The implica- 
tion of such contamination on the estimates of likely radiation exposure are not easily evaluated. If measurements on a contaminated badge are carried out distant from a contaminated spot, as was the normal practice at Sellafield, the dose from very penetrating radiation might be underestimated. It is believed, however, that most contamination has been caused by relatively non-penetrating radiations and that more than half of the dosimeters had contamination on the open window area of the film badge only, which would not affect the assessment of dose from penetrating radiation. Also, the films in contaminated dosimeters may continue to be irradiated even when the badge is not being worn-for example, overnightand the dose to the wearer might thus be overestimated. While it is not possible to quantify the effect on estimates of exposure, Kendall et al (paper in preparation) consider it more likely that the doses estimated from contaminated dosimeters would have been overestimated rather than underestimated.

In the study of the United Kingdom Atomic Energy Authority workforce it was estimated that the policy of recording as zero measured exposures that were below a certain threshold may have led to appreciable underestimation of exposures, especially in the early years of the study period (V Beral, personal communication; Beral et al, paper in preparation). ${ }^{7}$ This issue was much less important in our study, as the threshold dose was set much lower at Sellafield. It is understood that this did not reflect any technical difference between dosimeters, but rather a higher threshold set at the United Kingdom Atomic Energy Authority for managerial reasons (Kendall et al, paper in preparation).

\section{MORTALITY OF SELLAFIELD WORKERS COMPARED WITH GENERAL POPULATION}

The overall death rate of the Sellafield workers was very similar to that of the general population of England and Wales, standardised mortality ratios for all causes, for all cancers, and for causes other than cancer being 98, 95, and 100 , respectively. This was unexpected, as other studies of the mortality of workers by British Nuclear Fuels ${ }^{13}$ and studies of other groups of atomic energy workers in Britain ${ }^{7}$ and the United States ${ }^{415}$ had reported standardised mortality ratios substantially below 100 for deaths from all causes combined. In general these findings have been attributed to the "healthy worker" effect, it being common in occupational mortality studies to find overall death rates below those of the general population, as the latter group includes a proportion of long term chronically sick at relatively high risk of death and unlikely to be employed. Another manifestation of this effect is that death rates tend to be especially low in the period immediately after first employment, as people who are obviously sick are unlikely to be employed. This is perhaps especially likely to be the case at Sellafield, where a pre-employment medical examination has been the normal practice. Such an effect was present in this study, as in the year after first employment at Sellafield the standardised mortality ratio for all causes was 48 and in the firs five years combined was 70 ( 132 deaths observed $v 189$ expected; table $\mathrm{Vm}$ ). This effect was similar for all cancers combined and for causes other than cancer (standardised mortality ratios 76 and 68 , respectively).

To investigate to what extent the relatively high overall standardised mortality ratio among Sellafield workers might be due to high mortality in 0 north west England and Wales, where the plant is sited, we also estimated death rates for Cumberland and used these for comparison. Based on these rates the standardised mortality ratio for all causes of death for Sellafield $Q$ workers was reduced to 91 (table VIIIm). This reduction was due largely to the comparatively high mortality from circulatory diseases in Cumberland, $\Omega$ and especially ischaemic heart disease. Sellafield workers had death rates $\overline{\bar{J}}$ from this latter cause that were 19\% higher than the rates for England and Wales but slightly lower than those for Cumberland (table VIIIm). \& Standardised mortality ratios for all cancers combined and for individual $T$ cancers were similar whether the calculations were based on national or Cumberland rates (table VII).

Part of the explanation for the difference in findings between our study $\stackrel{\vec{S}}{\rightarrow}$ and other reports on workers at British Nuclear Fuels is the longer period of $\bar{C}$ follow up reported here. Clough reported on the mortality of Sellafield $\frac{\sigma}{\sigma}$ workers up to $1980 .{ }^{14}$ We have considered the period up to 1983 , and the $\bar{\sigma}$ standardised mortality ratio for 1981 to 1983 was higher than in earlier $\mathbb{Ð}$ periods (table IIIm)

By comparison with death rates for England and Wales there were substantially fewer than expected deaths among Sellafield workers from $\overrightarrow{0}$ infective and parasitic conditions and respiratory and digestive diseases:(table VIIIm), and there was also a significant deficit of deaths from liver and $\vec{\omega}$ gall bladder cancers. Apart from circulatory diseases, the only conditions showing a significant excess were mental disorders (11 observed $v 5.4$ 윽 expected) and cancers of ill defined and secondary sites ( 30 observed $v 19 \cdot 7$. expected). In both instances the excesses were most pronounced in non- No radiation workers and were thus unlikely to have arisen as a consequence of $\omega$ radiation exposure (tables VII and VIIIm). The 11 deaths from mental of disorders included six from senile dementia and four related to alcoholism. $\rightarrow$ The 30 deaths from ill defined or secondary cancers included 21 from $\infty$ carcinomatosis and four from abdominal cancers of unknown site.

In summary, the death rates of people who had worked at Sellafield were similar to those of the general population of England and Wales and about $9 \%$ lower than those of the population of Cumberland. Death rates due to cancer were similar in all three groups. We cannot explain the significant deficit of deaths from liver and gall bladder cancers or the excess of deaths $\overparen{O}$ from cancer of ill defined and secondary sites among non-radiation workers, which may be chance findings. The "healthy worker" effect appears to have been weaker than in other studies of nuclear workers, ${ }^{4715}$ though this might $\mathscr{\odot}$ be the explanation for the low standardised mortality ratios from infective o and parasitic, respiratory, and digestive diseases. The "healthy worker" effect is not well understood, however, making it difficult to interpret variations in its apparent magnitude among different industrial cohorts. The effect is usually associated with causes of death other than cancer (except in the first few years after employment) and thus the apparently normal

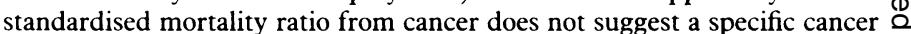
hazard among Sellafield workers. Possibly, however, an increased mortality $\overrightarrow{\overrightarrow{0}}$ due to occupational causes is being masked by a reduced risk from other, $\frac{0}{3}$ social causes of cancer. Evidence of a specific deleterious effect for radiation $\checkmark$ exposure at Sellafield may better be sought, therefore, by comparing the mortality of workers at the plant with different levels of exposure to radiation.

TABLE XII-Deaths from selected causes among radiation workers by radiation dose accumulated 15 or more years previously (adjusted for age, sex, calendar period, and industrial state). (Figures in parentheses are expected distribution of deaths assuming no relation between accumulated dose and mortality risk.) [Figures in square brackets are expected numbers of deaths based on death rates in England and Wales]

\begin{tabular}{|c|c|c|c|c|c|c|c|c|c|c|c|c|c|c|c|c|}
\hline \multirow{3}{*}{$\begin{array}{c}\begin{array}{c}\text { Cause of death } \\
(\text { ICD codes }(8 \text { th revision }))\end{array} \\
\text { Carcinoma bladder }(188)\end{array}$} & \multicolumn{13}{|c|}{ Radiation dose monitored (mSv) (lagged by 15 years) } & \multirow{2}{*}{\multicolumn{2}{|c|}{$\begin{array}{l}\text { Total } \\
\text { deaths }\end{array}$}} & \multirow{2}{*}{$\begin{array}{l}\mathrm{z} \text { Value for trend } \dagger \\
\text { (simulated } \mathrm{p} \text { value) }\end{array}$} \\
\hline & \multicolumn{2}{|c|}{$<10$} & \multicolumn{2}{|c|}{10} & \multicolumn{2}{|c|}{$20-$} & \multicolumn{2}{|c|}{50} & \multicolumn{2}{|c|}{$100-$} & \multicolumn{2}{|c|}{200} & $\geqslant 400$ & & & \\
\hline & & $\begin{array}{l}(4 \cdot 8) \\
{[6 \cdot 2]}\end{array}$ & 2 & $\begin{array}{l}(0 \cdot 9) \\
{[1 \cdot 0]}\end{array}$ & 1 & $\begin{array}{l}(2 \cdot 3) \\
{[2 \cdot 2]}\end{array}$ & 1 & $\begin{array}{l}(2 \cdot 0) \\
{[1 \cdot 8]}\end{array}$ & 3 & $\begin{array}{l}(1.9) \\
{[1.5]}\end{array}$ & 2 & $\begin{array}{l}(1.4) \\
{[1.0]}\end{array}$ & $\begin{array}{l}2(0 \cdot 7) \\
{[0 \cdot 4]}\end{array}$ & & $\begin{array}{l}(14 \cdot 0) \\
{[14 \cdot 2]}\end{array}$ & $2 \cdot 13\left(p=246 / 10^{4}\right)$ \\
\hline Multiple myeloma (203) & & $\begin{array}{l}(3 \cdot 2) \\
{[1 \cdot 8]}\end{array}$ & 0 & $\begin{array}{l}{[1.01} \\
(0.4) \\
{[0.3]}\end{array}$ & 1 & $\begin{array}{l}(0.9) \\
{[0.6]}\end{array}$ & 2 & $\begin{array}{l}110] \\
(0 \cdot 8) \\
{[0 \cdot 5]}\end{array}$ & 0 & $\begin{array}{l}(1.8) \\
(0.5) \\
{[0.5]}\end{array}$ & 0 & $\begin{array}{l}(0.7) \\
{[0.3]}\end{array}$ & $2(0 \cdot 2)$ & 7 & $\begin{array}{r}(7 \cdot 0) \\
{[4 \cdot 2]}\end{array}$ & $2 \cdot 66\left(p=115 / 10^{4}\right)$ \\
\hline Leukaemia (204-209) & & $\begin{array}{l}(6 \cdot 0) \\
{[6 \cdot 8]}\end{array}$ & 0 & $\begin{array}{l}(0 \cdot 7) \\
{[0 \cdot 8]}\end{array}$ & 3 & $\begin{array}{l}(1 \cdot 4) \\
{[1 \cdot 5]}\end{array}$ & 0 & $\begin{array}{l}(1 \cdot 1) \\
{[1 \cdot 2]}\end{array}$ & 0 & $\begin{array}{l}(0 \cdot 6) \\
{[1 \cdot 0]}\end{array}$ & 0 & $\begin{array}{l}(0.3) \\
{[0.6]}\end{array}$ & $\begin{array}{ll}1 & (0.04) \\
& {[0.22]}\end{array}$ & 10 & $\begin{array}{l}(10 \cdot 0) \\
{[12 \cdot 2]}\end{array}$ & $1 \cdot 76\left(p=599 / 10^{4}\right)$ \\
\hline All lymphatic and haematopoietic carcinomas (200-209) & & $\begin{array}{l}(12 \cdot 8) \\
{[16 \cdot 4]}\end{array}$ & 1 & $\begin{array}{l}(1.9) \\
{[1.9]}\end{array}$ & 5 & $\begin{array}{l}(4 \cdot 0) \\
{[3 \cdot 6]}\end{array}$ & 2 & $\begin{array}{l}(3 \cdot 4) \\
{[2 \cdot 9]}\end{array}$ & 2 & $\begin{array}{l}(2 \cdot 7) \\
{[2.5]}\end{array}$ & 1 & $\begin{array}{l}(1 \cdot 7) \\
{[1 \cdot 6]}\end{array}$ & $\begin{array}{ll}3(0.5) \\
& {[0.5]}\end{array}$ & 27 & $\begin{array}{l}(27 \cdot 0) \\
{[29 \cdot 4]}\end{array}$ & $2 \cdot 04\left(p=345 / 10^{4}\right)$ \\
\hline All malignant neoplasms (140-209) & 180 & $\begin{array}{l}(181 \cdot 9) \\
201 \cdot 2]\end{array}$ & 20 & $\begin{array}{l}(26 \cdot 9) \\
{[30 \cdot 1]}\end{array}$ & 54 & $\begin{array}{l}(57 \cdot 1) \\
{[59 \cdot 8]}\end{array}$ & 54 & $\begin{array}{l}(48 \cdot 4) \\
{[48 \cdot 6]}\end{array}$ & 47 & $\begin{array}{l}(42 \cdot 2) \\
{[41 \cdot 8]}\end{array}$ & 30 & $\begin{array}{l}(28 \cdot 9) \\
{[27 \cdot 7]}\end{array}$ & $\begin{array}{r}11(10 \cdot 6) \\
{[9 \cdot 6]}\end{array}$ & 396 & $\begin{array}{l}(396 \cdot 0) \\
{[418 \cdot 9]}\end{array}$ & 0.72 \\
\hline All causes & $\begin{array}{r}696(7 \\
{[7}\end{array}$ & $\begin{array}{l}707 \cdot 5) \\
794 \cdot 4]\end{array}$ & $\begin{array}{r}105( \\
{[}\end{array}$ & $\begin{array}{l}104 \cdot 1) \\
111 \cdot 9]\end{array}$ & 205 & $\begin{array}{l}218 \cdot 1) \\
225 \cdot 5]\end{array}$ & 194 [1 & $\begin{array}{l}186 \cdot 6) \\
185 \cdot 8]\end{array}$ & 174 & $\begin{array}{l}157 \cdot 2) \\
152 \cdot 6]\end{array}$ & 102( & $\begin{array}{l}103 \cdot 8) \\
{[98 \cdot 9]}\end{array}$ & $\begin{array}{r}40(38 \cdot 7) \\
{[34 \cdot 8]}\end{array}$ & 1516 & $\begin{array}{l}1516 \cdot 0) \\
1603 \cdot 9]\end{array}$ & $0 \cdot 72$ \\
\hline Person years at risk & 154 & 4535 & & 001 & & 566 & & 236 & & 547 & & 246 & 1231 & & 362 & \\
\hline
\end{tabular}

†See footnote to table $X$.

Conversion: SI to traditional units-Radiation dose: $10 \mathrm{mSv} \approx 1 \mathrm{rem}$ 
MORTALITY OF WORKERS EXPOSED TO DIFFERENT DOSES OF RADIATION

Death rates from all causes combined were lower among radiation workers than non-radiation workers (table VIIIm). For all cancers combined death rates were similar in the two groups (table VII). In general death rates were higher among "industrial" than "non-industrial" workers, but for men there were similar proportions of these two categories in the radiation and nonradiation groups. For women a higher proportion of those monitored were classified as industrial workers. Nevertheless, as the proportion of women in the study was relatively small, this is unlikely to have had a pronounced effect on the comparisons shown in tables VII and VIIIm. The results were not materially changed when the comparisons were restricted to men.

In no instance for cancers of individual sites was there a significant difference in standardised mortality ratios between radiation and nonradiation workers; nevertheless, most of these comparisons were based on relatively small numbers of deaths (table VII). In general for non-neoplastic conditions radiation workers had lower death rates than other workers, and for none of the causes listed in table VIIIm was the standardised mortality ratio for radiation workers significantly higher than that for other workers.

The only significant evidence of trends in standardised mortality ratios with increasing duration of employment was an increasing trend for stomach cancer among non-radiation workers and a decreasing trend for deaths from accidents and violence among radiation workers. Neither of these effects was likely to be a direct consequence of exposure to radiation.

That there were differences in the death rates of radiation and other workers (table VIIIm) suggests that there was a tendency to select as radiation workers people who had, on average, a lower mortality risk than other workers. For example, the mortality from bronchitis was noticeably lower among radiation workers. There are many possible explanations for such an effect, but three possibilities are that people with chronic bronchitis were less likely to become radiation workers, that radiation workers were of higher socioeconomic state, and that smoking was less common among radiation workers. Differences such as these may bias the interpretation of mortality comparisons between radiation and other workers. Mortality comparisons which are less likely to be susceptible to such bias are those between radiation workers who have accumulated different levels of exposure during their employment. The possibility of similar bias cannot be excluded, but its magnitude is likely to be smaller.

That such biases may be present is suggested by the finding that when mortality rates were compared within the group of radiation workers there was a significant negative association between mortality and the accumulated radiation dose monitored (table XI). This effect was most pronounced for respiratory diseases and, within these, for deaths from bronchitis. A likely explanation is that workers who develop chronic bronchitis, and possibly similar longstanding conditions associated with higher than average mortality rates, are taken off radiation work and thus when they die have accumulated lower than average radiation doses. The negative association between mortality from all causes and accumulated radiation dose was no longer present when doses accumulated in the preceding 15 years were excluded, and this finding is consistent with the effect postulated above, in that "unhealthy" workers are less likely to be selected out 15 years in advance of their death than they are within shorter periods. The negative associations between accumulated radiation dose and mortality from bronchitis was no longer pronounced nor statistically significant when the monitored exposure was lagged by 15 years.

For all cancers combined and for cancers of individual sites there were no statistically significant associations between mortality risk and the radiation doses monitored up to the time of death (table $\mathrm{X}$ ). A common finding in studies of radiation carcinogenesis, however, has been of an interval after exposure to radiation in which there is no apparent increased risk of cancer. For leukaemia this interval may be of the order of two years but for cancers of other sites it may be 10 or 15 years. If this is so radiation exposure accumulated within this interval may be unrelated to any cancers induced (though it is possible to conceive of mechanisms whereby such exposure may either enhance or depress the subsequent risk of cancer). Hence we also present in tables X and XII the results of analyses in which radiation doses monitored were lagged by two and 15 years. Lagging the monitored exposures by two years made little difference to the findings and, in particular, the association between risk of leukaemia and accumulated dose, though still positive, was not statistically significant. Lagging the exposures by 15 years, however, produced a more pronounced effect, and statistically significant positive associations were found between accumulated radiation doses and mortality from cancer of the bladder, myeloma, and all lymphatic and haematopoietic neoplasms combined (table XII).

We had expected that the association with leukaemia, if found at all, would be more pronounced when radiation dose was lagged by two years, as this would be consistent with effects reported in groups followed up after exposure to large doses of radiation. We also examined the association between the risk of death from leukaemia and the radiation dose accumu- lated between two and 20 years before death, as most radiation induced leukaemias have been reported in this period after exposure ${ }^{16}$ but the trend of risk with accumulated dose was not statistically significant ( $z$ statistic $=1 \cdot 13$ ). The association of dose with risk of leukaemia shown in table XII was largely attributable to one worker who accumulated a dose of over $400 \mathrm{mSv}$ ( $40 \mathrm{rem}$ ) up to 15 years before his death, certified as due to stem cell leukaemia. The appendix gives the details of this case and other deaths from neoplasms of the lymphatic and haematopoietic systems among radiation workers.

Analyses of the mortality of workers at the Hanford nuclear facility showed an association between deaths from myeloma and radiation dose accumulated up to two years before death ${ }^{6}$ and also for dose accumulated up to 10 years before death. ${ }^{5}$ Beral et al also found a positive association with the radiation dose accumulated up to the time of death among United Kingdom Atomic Energy Authority workers, but this was not statistically significant. Among Sellafield workers the association reached statistical significance when recorded yearly doses were lagged by 15 years (the association was weaker when doses were lagged by 10 years but stronger when lagged by 20 years). That it is appropriate to lag doses for this type of cancer by some period greater than 10 years is suggested by the late occurrence of excess deaths from myeloma among atomic bomb survivors in Japan, ${ }^{17}$ in patients irradiated for spondylitis (S C Darby et al, paper in preparation), and among women irradiated for cancer of the cervix. ${ }^{18}$ Though the overall mortality from myeloma among monitored workers at Sellafield was not significantly in excess of that expected from national mortality rates (seven observed $v$ $4 \cdot 2$ expected; table VII), taken together with the results from studies on the Hanford workers our findings suggest a dose related risk of myeloma among radiation workers.

Beral et al did not report data for bladder cancer for United Kingdom Atomic Energy Authority workers, ${ }^{7}$ and Gilbert found no association between deaths from this cause among Hanford workers and radiation dose accumulated up to 10 years previously. ${ }^{19}$ Many different causes of death were examined in our study and some "significant" associations are likely to have arisen by chance. Possibly the association with bladder cancer. is one such. We found no evidence of an association between deaths from cancer of the prostate and accumulated radiation dose with any of the lag periods examined (table $\mathrm{X}$ ) and thus our findings do not confirm the association reported by Beral et al for this cancer-due possibly to less exposure in Sellafield to specific radionuclides, which they suggested might be implicated, or possibly because their finding was due to chance.

\section{Conclusions}

The International Commission on Radiological Protection estimated that the risk of radiation induced leukaemia is about $20 / 10 \mathrm{mSv} / 10^{6}$ population (that is, one million people each exposed to $10 \mathrm{mSv}$ would result in about 20 cases of induced leukaemia) and for all cancers is about $100 / 10 \mathrm{mSv} / 10^{6}$. If we assume that these risks are experienced in the 20 years after exposure the estimated yearly induction rates are one per million per $10 \mathrm{mSv}$ and five per million per $10 \mathrm{mSv}$ for leukaemia and all cancers, respectively. About 10000 workers were monitored for external radiation exposure at Sellafield and they were recorded as accumulating, on average, about $124 \mathrm{mSv}(12.4 \mathrm{rem})$ each. Thus if each was followed up for 20 years after their last exposure an excess of about two or three leukaemias and a total of 10 to 15 radiation induced cancers would be expected on the basis of the International Commission on Radiological Protection estimates. These numbers must be contrasted with the deaths expected from other causes-about 12 from leukaemia and 420 from all cancers (table VII). Thus it was clear from the start of the study that if the commission's estimates were more or less correct this study would have little chance of detecting a significant excess of mortality from cancer or leukaemia among Sellafield workers. For all cancers combined we have estimated that the $95 \%$ confidence interval on excess risk associated with a $10 \mathrm{mSv}$ $(0 \cdot 1 \mathrm{rem})$ increment in dose with no lag period is from about -22 to 13 per million person years at risk per $10 \mathrm{mSv}$, the upper limit being just over twice the commission's estimate. If a given dose is assumed to induce cancers only 15 or more years later the estimate of the excess risk is 17 per million person years at risk per $10 \mathrm{mSv}$ with an upper $95 \%$ confidence limit of 70 (that is, about three times and 14 times the commission's estimate, respectively) and a lower $95 \%$ confidence limit of -30 . These figures should be treated with caution, however, given the limitations of epidemiological studies of the kind conducted. 
Firstly, the choice of appropriate comparison groups is difficult. We have argued that comparison of the death rates of Sellafield workers with those of the general population of England and Wales may be biased because of regional differences in mortality and the selection of healthier people for employment. Comparison with estimated death rates in Cumberland overcomes, in part, only the first of these potential biases, though the "healthy worker" effect is usually most pronounced for causes of death other than cancer. Within the plant itself radiation workers had lower death rates than other workers, and this difference is most unlikely to have been directly attributable to exposure to radiation. The main comparisons have focused, therefore, on radiation workers exposed to different doses of radiation. Unfortunately, we cannot exclude the possibility that workers accumulating different doses of radiation may be at differential risk of dying for reasons other than their exposure to radiation. Such differences may either obscure or enhance the magnitude of apparent radiation effects.

There are further limitations related to the measurement of radiation exposure. Firstly, only external radiation exposures are considered in this report. We hope that data on internal exposures will be available for analysis shortly, but it may be difficult to obtain reliable estimates of doses to different organs. We cannot exclude the possibility that internal radiation exposures may confound some of the associations that we have examined. Secondly, though it is rare in occupational studies of mortality to have dose histories which are as carefully recorded as is possible in studies of radiation workers, the uncertainties associated with the recorded doses are not inconsiderable. The dose recorded at the site on the body where the dosimeter is worn may be different from that to which other parts of the body are exposed. Also the procedures used to estimate the radiation doses from the dosimeter readings may be subject to error-as may be the case, for example, for "contaminated" dosimeters (as discussed under dosimetry). These inaccuracies are most likely to have the effect of obscuring a relation between exposure to radiation and induction of cancer. Thus the confidence intervals given above on the possible magnitude of the carcinogenic effects of the radiation exposure received by Sellafield workers are likely to be too narrow.

Clearly, when small effects are predicted there is much to be gained by combining the results of studies on similar groups of workers, and we hope that it will be possible to conduct a further analysis of the combined mortality experience of the United Kingdom Atomic Energy Authority and Sellafield workforces, together with that of other radiation workers in Britain.

In conclusion, there is no evidence that workers at the Sellafield plant have had a death rate from cancer substantially in excess of that of people of similar age and sex in Cumberland or elsewhere in England and Wales. Furthermore, among radiation workers there was no strong evidence of an association between mortality from all kinds of cancer combined and the external radiation dose accumulated up to the time of death or up to two or 15 years before death. There were, however, positive associations between the recorded external radiation dose and deaths from multiple myeloma, leukaemia, all lymphatic and haematopoietic neoplasms combined, and bladder cancer, which were strongest when mortality was related to radiation accumulated more than 15 years previously.

This investigation was supported by the Imperial Cancer Research Fund and through a grant to the London School of Hygiene and Tropical Medicine by British Nuclear Fuels. We are grateful to the many people who have given considerable help with this study. As well as those mentioned in the text, we thank Mary Burgess and Kate Hughes, of the Imperial Cancer Research Fund, for their extensive clerical and statistical help; Gerry Kendall, of the National Radiological Protection Board, for advice on dosimetry; and Steve Barry and Julian Peto for allowing us access to computer programs that they developed. The staffs of the NHS Central Register, the medical statistics division of the Office of Population Censuses and Surveys, and the national insurance records branch of the DHSS gave us great help. We are also particularly grateful to many colleagues who advised us at various times or commented on a draft of the paper. These included Abe Adelstein, Valerie Beral, Sarah Darby, Richard Doll, John Fox, Martin Gardner, Dave Gee, Hazel Inskip, Robin Mole, and Geoffrey Rose. We thank the staff of British Nuclear Fuels with whom we liaised to assemble the data for analysis, especially Eddie Clough, Paul Groom, Keith Binks, and the late Geoffrey
Schofield. A special debt is owed to Peggy Loy, who came out of retirements to code over 2000 death certificates. We thank Helen Edwards and Tină Organ for their considerable typing and secretarial help, and Jill Routledg for general support.

APPENDIX-Deaths from lymphatic and haematopoietic neoplasms among radiation workers

\begin{tabular}{|c|c|c|c|c|c|c|}
\hline $\begin{array}{l}\text { Case } \\
\text { No }\end{array}$ & $\begin{array}{l}\text { Age and } \\
\text { sex at } \\
\text { death }\end{array}$ & $\begin{array}{l}\text { Year of } \\
\text { death }\end{array}$ & $\begin{array}{l}\text { Period of } \\
\text { employment } \\
\text { at Sellafield }\end{array}$ & $\begin{array}{l}\text { Cause of } \\
\text { death }\end{array}$ & $\begin{array}{r}\text { Total radia } \\
\text { dose recor } \\
(\mathrm{mSv})\end{array}$ & atiog \\
\hline \multicolumn{7}{|c|}{ Leukaemia (ICD codes (8th revision) 204-209) } \\
\hline 1 & $49 M$ & 1956 & $1949-56$ & Chronic lymphatic & $5 \cdot 6$ & \\
\hline 2 & $58 \mathrm{M}$ & 1960 & $1953-60$ & Chronic myeloid & $152 \cdot 0$ & \\
\hline 3 & $53 \mathrm{M}$ & 1965 & $1953-65$ & Acute lymphoblastic & $116 \cdot 3$ & \\
\hline 4 & $36 \mathrm{M}$ & 1971 & $1957-70$ & Acute myeloid & $306 \cdot 7$ & \\
\hline 5 & $58 \mathrm{M}$ & 1973 & $1949-63$ & Myelofibrosis & $57 \cdot 5$ & 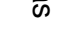 \\
\hline 6 & $75 \mathrm{M}$ & 1974 & $1949-64$ & Stem cell & $766 \cdot 5$ & \\
\hline 7 & $49 M$ & 1975 & $1951-75$ & Chronic myeloid & $411 \cdot 6$ & \\
\hline 8 & $38 \mathrm{M}$ & 1976 & 1958-66 & Chronic myeloid & $43 \cdot 0$ & \\
\hline 9 & $42 M$ & 1980 & $1962-80$ & Leucoerythroblastic anaemia & $14 \cdot 4$ & \\
\hline 10 & $45 \mathrm{M}$ & 1983 & $1961-64$ & Acute myeloid & $6 \cdot 3$ & \\
\hline \multicolumn{7}{|c|}{ Multiple myeloma (ICD code 203) } \\
\hline 11 & $45 \mathrm{M}$ & 1959 & $1949-59$ & Multiple myeloma & $41 \cdot 7$ & \\
\hline 12 & $51 \mathrm{M}$ & 1960 & $1947-60$ & Multiple myeloma & $32 \cdot 3$ & \\
\hline 13 & $55 \mathrm{M}$ & 1975 & $1949-75$ & Multiple myeloma & $565 \cdot 1$ & \\
\hline 14 & $58 \mathrm{M}$ & 1978 & $1949-54$ & Multiple myeloma & $67 \cdot 1$ & \\
\hline 15 & $54 \mathrm{M}$ & 1983 & $1964-82$ & Multiple myeloma & $119 \cdot 2$ & \\
\hline 16 & $67 M$ & 1983 & $1950-81$ & Multiple myeloma & $865 \cdot 7$ & \\
\hline 17 & $59 M$ & 1983 & $1951-61$ & Multiple myeloma & $67 \cdot 9$ & \\
\hline \multicolumn{7}{|c|}{ Lymphomas (ICD codes 200-202) } \\
\hline 18 & $30 M$ & 1964 & $1961-64$ & Reticulum cell sarcoma & $30 \cdot 3$ & \\
\hline 19 & $50 \mathrm{M}$ & 1970 & $1959-70$ & Lymphosarcoma & $4 \cdot 8$ & \\
\hline 20 & $75 \mathrm{M}$ & 1971 & $1957-61$ & Malignant lymphoma & $19 \cdot 3$ & \\
\hline 21 & $61 \mathrm{M}$ & 1971 & $1950-71$ & Lymphosarcoma & $514 \cdot 4$ & \\
\hline 22 & $61 \mathrm{M}$ & 1975 & $1949-54$ & Malignant lymphoma & $18 \cdot 7$ & \\
\hline 23 & $44 M$ & 1976 & $1960-61$ & Hodgkin's disease & 0.8 & \\
\hline 24 & $64 M$ & 1978 & $1950-77$ & Malignant lymphoma small & & \\
\hline & & & & intestines & $\begin{array}{l}188 \cdot 8 \\
209 \cdot 5\end{array}$ & \\
\hline 25 & $53 \mathrm{M}$ & 1979 & $1950-61$ & Generalised follicular lymphoma & $209 \cdot 5$ & \\
\hline 26 & $75 \mathrm{M}$ & 1983 & $1950-52$ & Lung lymphoma & 4.5 & \\
\hline 27 & $56 M$ & 1983 & $1959-63$ & Non-Hodgkin's lymphoma & $39 \cdot 8$ & \\
\hline
\end{tabular}

Conversion: SI to traditional units-Radiation dose: $10 \mathrm{mSv} \approx 1$ rem.

\section{References}

1 International Commission on Radiological Protection. Recommendations of the Internationa Commission on Radiological Protection. Ann ICRP 1977;1: No 26.

Commission on Radiological Protection. Ann ICRP $1977 ; 1:$ No 26 .
Land C. Estimating cancer risks from low doses of ionizing radiation. Science 1980;209:1197-203.

3 Mancuso TF, Stewart A, Kneale G. Radiation exposures of Hanford workers dying from cance and other causes. Health Phys 1977;33:369-85.

4 Gilbert ES, Marks S. An analysis of the mortality of workers in a nuclear facility. Radiat R 1979;79:122-48

5 Darby SC, Reissland JA. Low levels of ionizing radiation and cancer-are we underestimating the risk? Fournal of the Royal Statistical Society A 1981;144:298-331. 6 Tolley HD, Marks S, Buchanan JA, Gilbert ES. A further update on the analysis of mortality

7 Beral V, Inskip H, Fraser P, Booth M, Coleman D, Rose G. Mortality of employees of the Unite $\Phi$ Kingdom Atomic Energy Authority, 1946-1979. Br Med J 1985;291:440-7.

8 Black D. Investigation of the possible increased incidence of cancer in West Cumbria. Report of a

independent advisory group. London: HMSO, 1984 .
National Radiological Protection Board (Darby SC, ed). Protocol for the National Registry

Radiation Workers. Oxon: Harwell, 1981. (NRPB-R116.)
10 World Health Organisation. International classification of diseases. 8th revision, 1965. Vol Geneva: WHO, 1967.

11 Gardner MJ, Winter PD, Taylor CP, Acheson ED. Atlas of cancer mortaliy in England and Wale 1968-1978. Chichester: Wiley, 1983.

12 Gardner MJ, Winter PD, Barker DJP. Atlas of mortality from selected diseases in England and Wale 1968-1978. Chichester: Wiley, 1984.

13 Clough EA. The BNFL radiation-mortality study. Joumal of the Society for Radiological Protectiont 1983;3(1):24-7. $1983 ; 3(1): 24-7$.
Radiological Protection 1983;3(3):18-20.

15 Checkoway H, Mathew RM, Shy CM, et al. Radiation, work experience, and cause specifie mortality among workers at an atomic energy research laboratory. Br $\mathcal{F}$ Ind Med 1985;42 525-33.

16 Committee on the Biological Effects of Ionizing Radiations. The effects on populations of exposure $\frac{1}{\mathrm{~W}}$ low levels of ionizing radiation: 1980. Washington DC: National Academy Press, 1980.
adiation Effects Research Foundation. Life span study report 9, 1950-1978. Supplementary table: Hiroshima: Radiation Effects Research Foundation, 1980.

18 Boice JD, Day NE, Anderson A, et al. Second cancer following radiation treatment for cervical cancer. An international collaboration among cancer registries. $f N C I$ 1985;74:955-75.

19 Gilbert ES. How much can be learned from populations exposed to low levels of radiation. Th
Statistician 1985;34:19-30.

(Accepted 5 August 1986) 